BERNAL DEL CASTILLO, Jesús. "Política Criminal en España y discriminación xenófoba: la centralidad de los delitos de provocación a la discriminación". Polít. crim. Vol. 9, № 18 (Diciembre 2014), Art. 3, pp. 371-399. [http://www.politicacriminal.cl/Vol_09/n_18/Vol9N18A3.pdf]

\title{
Política Criminal en España y discriminación xenófoba: la centralidad de los delitos de provocación a la discriminación.
}

\author{
Jesús Bernal del Castillo \\ Profesor Titular de Derecho Penal. Universidad de Oviedo (España) \\ jbernal@uniovi.es
}

\section{Resumen}

El origen de la actual configuración multicultural en Europa se encuentra fundamentalmente en el masivo fenómeno inmigratorio. Las diferencias culturales y los problemas de integración de las minorías generan una notable conflictividad social, que reclama en sus manifestaciones más graves el recurso al Derecho Penal. Se hace necesario fundamentar la intervención penal en un modelo político criminal adecuado a la configuración política y social europea. Los modelos comunitario y liberal son sustituidos por una Política Criminal que toma como punto de referencia la protección del derecho a no ser discriminado, derivado de la dignidad de la persona y extensivo a la protección de los grupos o colectivos. Esta orientación se concreta en la tipificación de diversos delitos discriminatorios, entre los cuales destaca como referente central el delito de provocación a la discriminación. El estudio de este delito en el derecho español es un ejemplo de la necesidad de adelantar el Derecho Penal a conductas que entrañan una peligrosidad manifiesta de generar violencia y acciones discriminatorias.

Palabras clave: Política Criminal, antidiscriminación, provocación a la discriminación.

\begin{abstract}
Current multicultural societies in Europe have their origins in the massive immigration phenomenon. Cultural differences and problems of integration of minorities generate considerable social unrest, claiming in its more severe manifestations the recourse to criminal law. It is necessary to legitimize criminal law intervention in an appropriate criminal political model, adequate to European political and social settings. Community and liberal models are replaced by a Criminal Policy that takes as reference the protection of the right to non-discrimination, which is derived from the dignity of the person and the protection extended to groups or collectives. This orientation is specified in the definition of different discriminatory offenses, among which stands out as the central reference, the offense of incitement to discrimination. The study of this crime under Spanish law is an example of the need to advance the Criminal Law to behaviors that involve a manifest danger of generating violence and discriminatory actions.
\end{abstract}

Key words: Criminal Policy, counter-discrimination, incitement to discrimination. 
BERNAL DEL CASTILLO, Jesús. "Política Criminal en España y discriminación xenófoba: la centralidad de los delitos de provocación a la discriminación".

\section{Política Criminal y conflictos culturales}

La globalización social, como fenómeno característico de la historia contemporánea, presenta como una de sus manifestaciones más claras la generalización del fenómeno migratorio y la movilidad de personas. Una de las consecuencias del flujo migratorio actual es la formación de sociedades multiculturales en países que tradicionalmente podían calificarse de cultural y racialmente homogéneos, como es el caso de la mayor parte de los Estados europeos.

Al contrario de lo que ha sucedido en la mayoría de los países de América, el multiculturalismo europeo actual es un fenómeno reciente, que no aparece como producto de una colonización externa o de una mezcla de pueblos en los orígenes de los diversos Estados. Más bien es consecuencia de la fuerte inmigración procedente de países que en muchos casos no responden al canon cultural denominado occidental. ${ }^{1}$ Esta inmigración masiva ha generado el asentamiento en muchos países de fuertes minorías raciales, étnicas y culturales, dando lugar a nuevos retos políticos, sociales y éticos.

En este punto se hace necesario precisar qué se entiende por minorías culturales a los efectos de este trabajo. Utilizamos esta expresión para referirnos a aquellos grupos de personas que, generalmente por medio de la emigración o por razones de convivencia histórica, integran un colectivo diferenciado de la mayoría de la población, atendiendo a rasgos como la raza, etnia, nacionalidad, religión y al conjunto de valores axiológicos y sociales que podemos calificar como cultura. ${ }^{2}$ No es necesario que concurran todos estos elementos en dichos grupos pero sí alguno de ellos. De la misma forma tampoco integran un grupo cultural solamente los inmigrantes llamados de "primera generación", sino aquellas personas, cada vez más numerosas en Europa, descendientes de inmigrantes, que conservan la identidad cultural de sus padres y familias.

Uno de los principales problemas de la presencia de estas minorías está relacionado con su aceptación e integración en la sociedad mayoritaria y el choque con los principios y valores jurídicos y sociales vigentes en el país de acogida, cuestión que en Europa plantea serias distorsiones y conflictos sociales. No es objeto de este trabajo el estudio histórico o

\footnotetext{
${ }^{1}$ Fabio Basile distingue entre sociedades multiculturales de tipo "multinacional", por absorción en un país más grande de minorías nacionales autóctonas, territorialmente concentradas: Canadá, Australia, Estados Unidos, países sudamericanos..., de las sociedades multiculturales de tipo "poli-étnico", en las cuales el pluralismo cultural se origina por la inmigración de individuos y familias; BASILE, Fabio, "Il diritto penale nelle società multiculturali: i reati culturalmente motivati", Polít. crim., vol. 6, no 12 (2011), Art. 4, pp. 339386, en http://politicacriminal.cl/Vol_06/n_12/Vol6N12A4.pdf [visitado el 01.03.2014]. La configuración de los Estados europeos actuales como sociedades multiculturales responde en mi opinión a este segundo modelo, salvo casos excepcionales como sucede con las minorías gitanas o laponas.

${ }^{2}$ Sobre este concepto puede consultarse CARNEVALI RODRÍGUEZ, Raúl, "El multiculturalismo: un desafío para el Derecho Penal moderno", Polít. crim., $\mathrm{n}^{\mathrm{o}} 3$ (2007) A6, pp. 1-28, pp. 6 y 7, en http://www.politicacriminal.cl/n 03/a 6 3.pdf [visitado el 02.02.2014]. Comparto la opinión de Francesco Viola a la hora diferenciar entre multiculturalismo y pluralismo; VIOLA, Francesco, "Diritti fondamentali e multiculturalismo", en: BERNARDI, Alessandro (coord.) Multiculturalismo, diritti humani, pena, Milano: Giuffré, 2006, p. 37. Basile por su parte considera oportuno partir del concepto de cultura definido en el Preámbulo de la "Declaración universal de la Unesco sobre diversidad cultural", de 2 de noviembre de 2001; en BASILE, "Il diritto penale nelle società multiculturali", cit. en nota nº 1, pp. 346 y 347.
} 


\section{Polít. crim. Vol. 9, № 18 (Diciembre 2014), Art. 3, pp. 371-399. [http://www.politicacriminal.cl/Vol_09/n_18/Vol9N18A3.pdf]}

sociológico de este problema, sino su análisis jurídico y, especialmente, la necesidad de recurrir al Derecho Penal como medio de resolución de algunos conflictos entre mayorías y minorías culturales dentro de un mismo Estado, en concreto aquellos relacionados con el rechazo o aceptación de los grupos minoritarios por medio de conductas discriminatorias.

El punto de partida de este análisis se encuentra en afirmar la legitimidad del recurso al Derecho Penal respecto a los conflictos multiculturales, legitimidad que está hoy día firmemente definida en los textos internacionales que reconocen la necesidad de la protección de las minorías culturales. ${ }^{3}$ La normativa internacional ha impulsado en muchos Estados la iniciativa legislativa penal, legislación que responde a diversas orientaciones de Política Criminal. Desde una perspectiva comparada se suelen distinguir dos grandes modelos político criminales en relación a este tema, ${ }^{4}$ asentados en dos principios axiológicos diferentes, que se remiten en última instancia a dos concepciones diferentes del Estado: comunitario y liberal. Cada uno de estos modelos responde a la necesidad de enfocar los posibles conflictos penales desde una de las perspectivas anteriormente mencionadas. El modelo comunitario plantea una Política Criminal que integra dentro de las instituciones penales valores y principios dirigidos a hacer eficaces los derechos culturales minoritarios para resolver los conflictos entre mayorías y minorías. El modelo político criminal de corte liberal se centra fundamentalmente en resolver los problemas de discriminación.

\subsection{Modelo comunitario}

En muchos países donde la diversidad de culturas es un fenómeno inherente a la propia estructura social se ha extendido la defensa de un modelo comunitario integrador, que pone el acento en el deber del Estado de reconocer y promocionar a nivel jurídico, político y social la identidad cultural de las minorías y grupos culturales, actitud intervencionista fundamentada en diversos argumentos: bien en el reconocimiento de derechos culturales de minorías, bien en la necesidad de especial protección a las culturas más débiles, bien como fórmula de superación de actitudes históricas injustas.

Este modelo no ofrece un marco unitario en la promoción del multiculturalismo ni en sus planteamientos teóricos ${ }^{5}$ ni tampoco en las concretas políticas sociales y jurídicas adoptadas en la práctica. Se pueden poner como ejemplos diferentes del desarrollo de estas tendencias, por una parte las políticas de integración social llevadas a cabo en los Estados

\footnotetext{
${ }^{3}$ Por su importancia citamos entre la normativa de las Naciones Unidas el artículo 27 del Pacto Internacional de Derechos Civiles y Políticos (1996), el artículo 1, anexo 47, de la Declaración de Derechos de las personas pertenecientes a Minorías Nacionales, Étnicas, Religiosas o Lingüísticas (1992) y el artículo 4 de la Convención Internacional para la eliminación de todas las formas de discriminación racial (1965). En el ámbito europeo merece ser destacado por su importancia y su conexión con el tema de este trabajo, la Decisión Marco del Consejo de la Unión Europea 913/2008, de 28 de Noviembre, relativa a la lucha contra determinadas formas y manifestaciones de racismo y xenofobia mediante el Derecho Penal.

${ }^{4}$ Una exposición comparativa de ambos modelos la encontramos en JOPKE, Christian, "Minority Rights for Immigrants? Multiculturalism versus Antidiscrimination", Israeli Law Review, vol. 43 (2010), pp. 49-66.

${ }^{5}$ Ver JOPKE, "Minority Rights", cit. nota $\mathrm{n}^{\circ}$ 4, pp. 51 y 52, donde expone diferentes orientaciones teóricas multiculturales. En concreto menciona la gran influencia que han tenido en las mismas Charles Taylor y Will Kymlicka.
} 
BERNAL DEL CASTILLO, Jesús. "Política Criminal en España y discriminación xenófoba: la centralidad de los delitos de provocación a la discriminación”.

Unidos y Canadá bajo la perspectiva del principio de "discriminación positiva", y por otra, las iniciativas de reconocimiento -incluso a nivel constitucional- y la validez de instituciones políticas y jurídicas de las minorías indígenas en algunos países sudamericanos como Perú, Bolivia, Colombia y Ecuador.

En el ámbito del Derecho Penal, esta orientación de protección positiva de la diversidad cultural da origen a la adopción de principios y reglas dirigidas al reconocimiento y protección de lo que es culturalmente valioso y exigible (los llamados derechos o normas culturales), ${ }^{6}$ con medidas sustantivas y procesales de diversa naturaleza: en particular, a través de la definición de los delitos culturalmente motivados, reconociendo las denominadas defensas culturales o aplicando instituciones ya existentes en el Derecho Penal General etc. ${ }^{7}$ O bien, aceptando y proponiendo la coexistencia de sistemas jurisdiccionales diferentes dentro de las fronteras de un mismo Estado. ${ }^{8}$ Alguna de estas ideas que tienen un reconocimiento efectivo en muchos países, especialmente en Hispanoamérica, ${ }^{9}$ chocan en cambio con el modelo de Estado liberal, fundamentado en el principio de soberanía estatal de base territorial, principio que exige una unidad en los sistemas penales y jurisdiccionales como garantía del principio de igualdad. ${ }^{10}$ También algunos de estos planteamientos parece que entran en contradicción con la aceptación de la validez objetiva del sistema valorativo representado por los derechos humanos. ${ }^{11}$ De ahí que la idea de un modelo político criminal multicultural general parezca de difícil penetración en los ordenamientos europeos.

También el principio de subsidiariedad del Derecho Penal puede verse afectado por la adopción del modelo multicultural, que en principio implica la posibilidad de una Política Criminal expansiva e intervencionista por parte del Estado. No obstante, dicha posibilidad

\footnotetext{
${ }^{6}$ Sobre el concepto de derechos culturales CARNEVALI, "El multiculturalismo", cit. nota no 2, pp. 10 y ss.

${ }^{7}$ Ver, por ejemplo, el artículo de MODOLELL GONZÁLEZ, José Luis, "Breves consideraciones sobre la posible responsabilidad personal de sujetos pertenecientes a grupos culturalmente diferenciados (casos del indígena y costumbres de origen afroamericano)", Anuario de Derecho Penal, 2006, pp. 273-286, http://perso.unifr.ch/derechopenal/assets/files/anuario/an_2006_14.pdf

${ }^{8}$ Desde esta perspectiva ver la propuesta de un "sistema de justicia comunitaria", basado en el reconocimiento del derecho humano a la identidad cultural, expuesto por PORTILLA CONTRERAS, Guillermo; POMARES CINTAS, Esther, "Derecho Penal multicultural y el sistema de justicia comunitaria", en: BERNAL DEL CASTILLO, Jesús (dir.), Delito y minorías en países multiculturales, Barcelona: Ed. Atelier, 2014, pp. 231252, p. 238 y ss.

${ }^{9}$ Existen numerosos trabajos en Hispanoamérica sobre la influencia de las culturas indígenas en el Derecho Penal; Se puede encontrar una buena referencia a esta bibliografía en el artículo de CARNEVALI, "El multiculturalismo", cit. nota $n^{\circ}$ 2, especialmente pp. 7-9. En España algunos autores han estudiado también a fondo estas cuestiones. Sólo a título de ejemplo, se pueden citar entre otros los trabajos de BORJA JIMÉNEZ, Emiliano, "Sobre la existencia y principios básicos del Derecho penal indígena" y el resto de las colaboraciones que aparecen en el libro que él coordina titulado Diversidad cultural: conflicto y derecho, Valencia, Tirant Monografías, 2006, así como su monografía Introducción a los fundamentos del Derecho Penal indígena, Valencia: Tirant lo Blanch, 2000.

${ }_{10}$ Sobre la crisis del concepto de Estado-nación ver la opinión de DE MAGLIE, Cristina, I reati culturalmente motivati. Ideologie e modelli penali, Firenze: Ed. ETS, 2010 (traducción española de MACÍAS CARO, Víctor Manuel), Madrid: Marcial Pons, 2012.

${ }^{11}$ Plantea este problema entre otros autores SILVA SÁNCHEZ, Jesús, "Retos científicos y retos políticos de la Ciencia del Derecho Penal”, ¿Crisis del sistema dogmático del delito?, Cuadernos de Conferencias y artículos, $\mathrm{n}^{\circ} 40$ (2007), Universidad Externado de Colombia, p. 26
} 
Polit. crim. Vol. 9, № 18 (Diciembre 2014), Art. 3, pp. 371-399.

[http://www.politicacriminal.cl/Vol_09/n_18/Vol9N18A3.pdf]

es susceptible de ser evitada desde el propio modelo multicultural, entre otros motivos, porque la protección de los derechos de las minorías se puede llevar a cabo a través de otros sectores jurídicos y sociales previos o alternativos al Derecho Penal. Desde otra perspectiva, especialmente en los Estados Unidos, se mantiene el papel secundario del Derecho Penal en la protección de los valores y derechos culturales con el argumento de evitar la restricción del derecho a la libertad de expresión, ya que la excesiva tipificación de conductas en orden a la protección de las minorías culturales, implicaría una posible vulneración de los derechos de opinión.

No obstante, resulta innegable que el planteamiento de un Derecho Penal intercultural ha penetrado en cierta medida en Europa, defendiéndose desde distintas perspectivas la conveniencia de aceptar alguno de sus postulados, bien en el ámbito procesal ${ }^{12}$ bien en el ámbito del derecho penal sustantivo.

Sin embargo, en mi opinión, al menos en España, los principios de legalidad e igualdad vetan la posibilidad de reconocer sistemas jurisdiccionales alternativos en materia penal, haciéndose extensiva esta imposibilidad a la hora de apreciar penas diferentes a las legalmente establecidas. Sería posible en cambio, al menos teóricamente, apreciar la aplicación de la denominada defensa cultural (cultural defence) como forma de valorar la relevancia de la identidad cultural de una persona a la hora de determinar el injusto ${ }^{13}$ o la culpabilidad $^{14}$ en determinados delitos. Es discutible la necesidad de introducirla expresamente en el ordenamiento penal español, definiendo una causa de justificación o exculpación cultural autónoma por vía legislativa; parece más conveniente la aplicación de las circunstancias eximentes y atenuantes generales ya vigentes, en especial el recurso al error y al miedo insuperable, sobre todo cuando por su configuración se revelan idóneas y flexibles para comprender esos supuestos, ponderándose esta viabilidad en cada caso concreto por los tribunales de justicia. De esta forma como expone Roca Agapito, se sigue la orientación jurisprudencial que así resuelve estos casos en diversos países, especialmente en los tribunales norteamericanos. ${ }^{15}$

Cuestión distinta es el reconocimiento de los denominados derechos culturales colectivos o individuales. Entiendo que teniendo siempre como límite la dignidad de la persona y la validez objetiva de los derechos humanos tal y como se exige en las Declaraciones de

\footnotetext{
${ }^{12}$ Por ejemplo, Luigi, Cornacchia propone el modelo de justicia transicional para solucionar los conflictos penales multiculturales; ver CORNACCHIA, Luigi, "Justicia transicional en una sociedad multicultural", en: CORNACCHIA, Luigi; SÁNCHEZ-OSTIZ, Pablo (coords.), Multiculturalismo y Derecho Penal, Madrid: Aranzadi, 2012, pp. 69-80, pp. 77-79. Mario Ferreira Monte considera apropiado el sistema de justicia restaurativa; ver FERREIRA MONTE, Mario, "Multiculturalismo y Derecho Penal en el espacio lusófono. Prueba de una solución de restauración para el problema de los delitos motivados culturales", en: CORNACCHIA/SÁNCHEZ-OSTIZ, "Multiculturalismo y Derecho Penal", cit. nota n 12, pp. 117-130.

${ }^{13}$ A los derechos humanos como límite de la aceptación de las normas de cultura en orden a la determinación de la antijuridicidad material del delito, se refiere QUINTERO OLIVARES, Gonzalo, "El derecho penal de la globalización", en: ZÚÑIGA RODRÍGUEZ, Laura; MÉNDEZ RODRÍGUEZ, Cristina; DIEGO DÍAZSANTOS, Rosario, (coords.), El Derecho Penal ante la globalización, Madrid: Ed. Colex, 2002, pp. 11-25, especialmente pp. 19 y 20.

${ }^{14}$ Ver CARNEVALI, "El multiculturalismo" cit. nota n ${ }^{\circ} 2$, pp. 27 y 28.

15 ROCA DE AGAPITO, Luis, "Delitos culturalmente motivados", en: BERNAL DEL CASTILLO (dir.), "Delito y minorías en países multiculturales", cit. nota n 8, pp. 177-205, p. 193.
} 
BERNAL DEL CASTILLO, Jesús. "Política Criminal en España y discriminación xenófoba: la centralidad de los delitos de provocación a la discriminación".

Derechos y en las normas constitucionales, ${ }^{16}$ es necesario aceptar y desarrollar normativamente el derecho a integrarse en una sociedad más amplia dentro del propio marco y entorno cultural, tal y como lo define el artículo 27 del Pacto Internacional de Derechos Civiles y Políticos. ${ }^{17}$ Ello no implica necesariamente calificarlo como un derecho humano autónomo, ${ }^{18}$ sino como una de las consecuencias de los principios de dignidad personal y del libre desarrollo de la personalidad, reconociendo su validez como parte del contenido de otros derechos fundamentales: derecho a la libertad religiosa, educación, asociación, etc.

Esta forma de reconocer el derecho a la identidad cultural es importante a la hora de corregir la visión quizás demasiado estrecha del modelo político criminal liberal de protección de minorías, al que nos referimos a continuación.

\subsection{Modelo político criminal liberal}

El modelo liberal de protección de minorías se considera, con diversas variaciones, como el vigente en la mayoría de los países europeos. Se caracteriza por desarrollar una Política Criminal relativa a los problemas multiculturales centrada en la adopción de medidas antidiscriminatorias, sobre la base de la defensa de una igualdad formal ante la ley de todos los ciudadanos y residentes en el territorio de un Estado.

Este modelo político criminal enlaza en su origen con la concepción liberal clásica del Estado, que concibe la misión de las instituciones estatales como garantes de la posibilidad del ejercicio de los derechos comunes para todos los ciudadanos en condiciones de igualdad. Por ello, la intervención del Estado debe concretarse en la evitación de aquellas conductas que discriminan, es decir, que niegan o ponen en peligro el acceso de una persona al ejercicio de sus derechos por razones vinculadas a su ideología, raza, origen nacional, etc., lesionando de esta forma el principio de igualdad formal, principio consagrado como uno de los pilares del Estado liberal. ${ }^{19}$ Desde una perspectiva general, se puede decir que un Estado liberal estricto no tiene como misión la promoción positiva de la multiculturalidad ni tampoco el desarrollo de los derechos culturales específicos de determinados grupos o personas, sino que debe mantener una estricta neutralidad valorativa ante estos derechos.

\footnotetext{
${ }^{16}$ Entre los documentos que confirman la limitación que a los valores culturales impone la dignidad de la persona y sus derechos fundamentales se puede citar en el ámbito europeo el Preámbulo de la Carta de Derechos Fundamentales de la Unión Europea (2010/C/83/02), y en el derecho español el art. 3.2 de la Ley Orgánica 4/2000, de 11 de enero, sobre derechos y libertades de los extranjeros en España.

${ }^{17}$ Art. 27: "En los Estados en que existan minorías étnicas, religiosas o lingüísticas, no se negará las personas que pertenezcan a dichas minorías el derecho que les corresponde, en común con los demás miembros del grupo, a tener su propia vida cultural, a profesar o practicar su propia religión y a emplear su propio idioma".

${ }_{18}$ En cambio así lo consideran, por ejemplo, PORTILLA CONTRERAS y POMARES CINTAS, "Derecho Penal multicultural y el sistema de justicia comunitaria", cit. nota ${ }^{\circ}$ 7, pp. 236-238.

${ }^{19}$ Ver la explicación de este principio que realiza GARCIA VITORIA, Aurora, "Extranjería y discriminación: análisis dogmático y jurisprudencial", en: ZUGALDÍA ESPINAR, José Miguel; PÉREZ ALONSO, Esteban J. (dirs.), El Derecho Penal ante el fenómeno de la inmigración, Valencia: Tirant Lo Blanch, 2007, pp. 319363.
} 


\section{Polít. crim. Vol. 9, № 18 (Diciembre 2014), Art. 3, pp. 371-399. \\ [http://www.politicacriminal.cl/Vol_09/n_18/Vol9N18A3.pdf]}

Esta perspectiva liberal que informa la normativa europea hasta nuestros días, resulta coherente ante la fenomenología del multiculturalismo europeo, que ha tenido su causa en la llegada masiva de inmigrantes en las últimas décadas. Ante esta realidad, el primer paso en la protección de los inmigrantes ha sido garantizar su acceso en condiciones de igualdad a los derechos comunes a todos los ciudadanos y, desde este punto de vista, el principio liberal de la prohibición de discriminación en cuanto lesión de la igualdad ante la ley, ha constituido un punto de partida necesario. Jopke explica esta perspectiva señalando que propiamente los derechos que mejor garantizan el establecimiento en un país de los inmigrantes no son los derechos "poli-étnicos", sino "los derechos generales a la libertad de expresión y asociación, a la intimidad, a la vida familiar y a la libertad religiosa que el Estado liberal ofrece a todos los individuos, inmigrantes y nativos, ciudadanos y no ciudadanos". ${ }^{20}$

No obstante, debemos señalar que en su evolución más reciente, el modelo liberal clásico del tratamiento penal de las minorías debe ser sometido a revisión, fundamentalmente a causa de los cambios sociales producidos en Europa. Esta revisión no afecta a la orientación de la Política Criminal en materia de resolución de los conflictos multiculturales desde la óptica de la interdicción de la discriminación, perspectiva en la que insiste también la normativa impulsada por la Unión Europea. La evolución del Derecho Penal en esta materia se plantea más bien en términos de hacer más efectiva la normativa antidiscriminatoria.

Especialmente en las dos últimas décadas, el fenómeno de la inmigración se ha convertido en los países occidentales en un problema de multiculturalidad. En efecto, en nuestros días ya no se plantea en las sociedades europeas simplemente la necesidad de reconocer derechos civiles o ciudadanos a los inmigrantes, puesto que existe una normativa internacional y estatal específica en este sentido. Se trata más bien de afrontar el problema de su integración, en concreto la posibilidad de que convivan, dentro de marco jurídico y social común, grupos culturales, étnicos y religiosos diferentes, evitando dos extremos: que los grupos minoritarios se retraigan constituyendo las denominadas "sociedades paralelas", 21 o que sean obligados a renunciar a aquellos aspectos de su cultura o religión que no sean incompatibles con el mínimo común denominador que viene constituido por los derechos humanos y los principios constitucionales o normativos básicos de un Estado. Por otra parte, en la actualidad quiebra también el paradigma de la pretendida neutralidad del Estado ante los valores culturales, dado que se ha llevado en ocasiones hasta extremos no justificables y generadores de conflictos.

El primero de los objetivos: la integración de las minorías, es una necesidad apremiante, basada en la realidad de serios problemas sociales. Entre los más preocupantes cabe mencionar los siguientes: el aislamiento, voluntario o inducido, de grandes grupos étnicos o nacionales en muchos países europeos, sobre todo en el ámbito de las grandes ciudades; los enfrentamientos violentos; la repercusión en los índices de criminalidad; la aparición de

\footnotetext{
${ }^{20}$ JOPKE, "Minority Rights", cit. nota no 4, p. 53.

${ }^{21}$ CANO PAÑOS, Miguel Ángel "Las sociedades paralelas en Europa en el contexto de la inmigración y su eventual influencia en la radicalización islamista de sus miembros", en: BERNAL DEL CASTILLO (dir.) Delito y minorías en países multiculturales, cit. nota n 8 , pp. 207-229.
} 
BERNAL DEL CASTILLO, Jesús. "Política Criminal en España y discriminación xenófoba: la centralidad de los delitos de provocación a la discriminación”.

actitudes racistas o xenófobas por parte de grupos radicales; la mentalidad colectiva en ciertos momentos de miedo o prevención ante ciertas minorías, en concreto ante la comunidad musulmana, por causa del terrorismo radical islamista. ${ }^{22}$

Por otra parte, como ya he señalado, el principio de neutralidad del Estado ante los valores culturales de las minorías debe ser puesto entre paréntesis en la medida en que determinadas políticas llevadas a cabo en algunos Estados han desvirtuado su fundamento, que es precisamente evitar la discriminación entre iguales, que a estos efectos son todas las personas que residen en un país. En la práctica se ha causando algunas veces el efecto contrario, es decir, la discriminación respecto a determinados valores culturales, prohibiendo sus manifestaciones públicas y negando su legitimidad, por un malentendido afán de mantener el ámbito de la actividad pública alejada de valores que proceden, por ejemplo, de tradiciones o manifestaciones religiosas o culturales. ${ }^{23}$ Siendo un tema delicado, que requiere un discernimiento prudente, al mantener esa neutralidad valorativa a toda costa se cae en ocasiones en un extremismo incompatible con el reconocimiento legítimo de determinados valores religiosos y culturales, dando lugar a que se acuse al modelo estatal occidental de promover la integración de las culturas minoritarias asimilándolas a las mayorías. ${ }^{24}$

\subsection{Un tercer modelo político criminal: la sustantividad del derecho a no ser discriminado}

Ante la evolución de las sociedades occidentales se pueden plantear dos posibles vías para acercarse a estas nuevas exigencias del multiculturalismo en el ámbito del Derecho Penal.

Una puede consistir en la aceptación de los principios y propuestas propias del modelo comunitario, en el sentido que se ha expuesto en el apartado 1.1. Señalaba en ese lugar que si bien este modelo puede inspirar nuevas políticas sociales y jurídicas, sus presupuestos y principios no se corresponden en términos generales al modelo social y estatal propio de los países occidentales y, por ello, no parece que la Política Criminal actual, al menos en los países del entorno jurídico y cultural europeo, deba fundamentarse en el modelo

\footnotetext{
${ }^{22}$ Sobre alguna de estas cuestiones ver CANO PAÑOS, "Las sociedades paralelas en Europa", cit. nota $\mathrm{n}^{\circ}$ 18; SILVA SÁNCHEZ, Jesús María, La expansión del Derecho Penal. Aspectos de la política criminal en las sociedades postindustriales, $2^{\mathrm{a}}$ ed., Madrid: Ed. Cívitas, 2001, especialmente pp. 106-108; RETORTILLO OSUNA, Álvaro; OVEJERO BERNAL, Anastasio; CRUZ SOUSA, Fátima; LUCAS MANGAS, Susana; ARIAS MARTÍNEZ, Benito, "Inmigración y modelos de integración: entre la asimilación y el multiculturalismo", Revista Universitaria de Ciencias del Trabajo, $\mathrm{n}^{\circ} 7$ (2008), pp. 124-139, en http://www.ruct.uva.es/pdf/Revista\%207/7106.pdf [visitado el 01.04.2014].

${ }^{23}$ Este tipo de conflictos que se plantean entre aceptar determinadas tradiciones religiosas y culturales minoritarias o alejarlas del ámbito de la vida pública, se manifiestan especialmente en algunas cuestiones recurrentes en Europa, verdaderos casus belli, como es el supuesto del uso en lugares públicos del velo islámico o de símbolos religiosos en las escuelas públicas. Puede verse un tratamiento a fondo de las causas y argumentos alegados en este tipo de conflictos en el libro de SANTAMARÍA, Francisco ¿Un mundo sin Dios? La religión bajo sospecha, Madrid: Ed. Rialp, 2012. Más específicamente sobre el problema del velo islámico STOPLER, Gila, "Rights in Immigration: The veil case as a test case", Israeli Law Review, vol. 43 (2010), pp. 183-217.

${ }^{24}$ Un ejemplo de esta orientación estatal fundada en la asimilación es el de Francia, país que representa el extremo de esta postura a través de leyes como la ley n ${ }^{\circ}$ 228/2004, de 15 de marzo que prohíbe la ostentación de símbolos religiosos en la escuela en aras de una igualdad formal en el espacio público.
} 
Polit. crim. Vol. 9, № 18 (Diciembre 2014), Art. 3, pp. 371-399.

[http://www.politicacriminal.cl/Vol_09/n_18/Vol9N18A3.pdf]

comunitario, si bien pueden hacerse diversas excepciones en el ámbito del derecho penal sustantivo. Una de ellas puede ser la aceptación de la "motivación cultural" a la hora de fundamentar la aplicación de alguna circunstancia eximente o atenuante de la responsabilidad criminal.

Aun aceptando estas aportaciones del modelo comunitario, creo que la Política Criminal europea debe seguir una segunda orientación. En concreto se trata de mantener el modelo liberal de protección de las minorías centrado en la proscripción de la discriminación, pero con otro alcance, sobre todo a la hora de fundamentar la tipificación y los elementos de los delitos discriminatorios.

Es en este ámbito donde cobra autonomía el derecho a no ser discriminado como fundamento de la tipificación de conductas, dado que la perspectiva de la protección del principio de igualdad formal no ofrece una respuesta adecuada a la nueva perspectiva multicultural. De hecho, como hemos visto, la realidad sociológica en Europa va más allá de la promoción de la igualdad en el acceso a los derechos ciudadanos y sociales; se pretende un respeto hacia la persona con sus características personales y culturales en cuanto ejercita esos derechos en particular.

La raíz de la discriminación en situaciones de multiculturalidad es la actitud de desprecio hacia la persona misma por lo que representa su raza, etnia, religión u otras circunstancias personales. Desde esta perspectiva, el derecho a no ser discriminado implica algo más que la infracción del principio de igualdad, basado en un arbitrario trato desigual.

El reconocimiento de un derecho autónomo a la no discriminación es una idea que se puede deducir a partir de la normativa antidiscriminatoria internacional y, al menos en España, de la evolución de la jurisprudencia del Tribunal Constitucional. ${ }^{25}$ En concreto, a partir de la Declaración de Derechos Humanos de 1948, de los Pactos de Derechos civiles y políticos de 1966 y especialmente de la Convención Internacional sobre la eliminación de todas las formas de discriminación racial de 1965 (artículo 1.1), se van enumerando y ampliando tanto las causas o motivos que van a fundamentar la conducta de discriminación: raza, color, linaje nacional o étnico, etc., como el contenido del mismo hecho discriminatorio: distinción, exclusión o preferencia, así como la relación de estas conductas con la dignidad de la persona:

"En la presente Convención la expresión "discriminación racial" denotará toda distinción, exclusión, restricción o preferencia que tenga por objeto o por resultado anular o menoscabar el reconocimiento, goce o ejercicio, en condiciones de igualdad, de los derechos humanos y libertades fundamentales en las esferas política, económica, social, cultural o en cualquier otra esfera de la vida pública".

Progresivamente se va determinando que el núcleo de la gravedad de la discriminación no está únicamente en los derechos o libertades de las que se ve privada una persona y que la

\footnotetext{
${ }^{25}$ En este sentido, ver la argumentación de la sustantividad del derecho a no ser discriminado que defiende TAPIA BALLESTEROS, Patricia, La discriminación laboral. Análisis del artículo 314 del Código Penal, Valencia: Tirant Monografías, 2014, p. 110.
} 
BERNAL DEL CASTILLO, Jesús. "Política Criminal en España y discriminación xenófoba: la centralidad de los delitos de provocación a la discriminación".

colocan en una posición de desigualdad respecto de los demás ciudadanos, sino especialmente en la naturaleza de las razones que fundamentan ese trato discriminatorio y que ilegitiman las distinciones hechas. En este sentido es revelador el artículo 1.1 de Protocolo Adicional 12 del Convenio Europeo de Derechos Humanos y de Libertades Fundamentales:

"El goce de todos los derechos reconocidos por la ley han de ser asegurados sin discriminación alguna, en particular por razones de sexo, raza, color, lengua, religión, opiniones políticas o de otro carácter, origen nacional o social, pertenencia a una minoría nacional, fortuna, nacimiento o cualquier otra situación". ${ }^{26}$

Desde esta perspectiva de la protección del derecho a no ser discriminado se puede actualizar la política penal intervencionista actual, al menos en España. Para ello hace falta en primer lugar una delimitación conceptual de este derecho.

En este orden mantengo una fundamentación personalista del derecho a la no discriminación y, como consecuencia, una interpretación similar de los delitos discriminatorios. $^{27}$ De esta forma, la Política Criminal de origen liberal que en España ha girado en torno al principio de igualdad formal da un vuelco en el sentido de convertirse en una serie de acciones dirigidas a garantizar, mediante el recurso al Derecho Penal, aquella esfera de la dignidad de la persona que se ve vulnerada por el rechazo de un sujeto y de sus actividades a causa del desprecio hacia alguna de sus cualidades. Por lo tanto, mientras que la simple desigualdad en el trato se funda en la arbitrariedad, la discriminación va más allá, comporta una motivación o razón rechazable de lo que es propio del sujeto pasivo y que expresa su ser personal.

A partir de esta delimitación del derecho a no ser discriminado, se consigue de esta forma una mejor justificación del recurso al Derecho Penal, con una sustantividad de los bienes jurídicos penales afectados por la conducta discriminatoria más sólida que la referencia a la lesión del principio de igualdad formal y una actitud positiva por parte del Estado hacia la pertenencia de una persona a un grupo minoritario. ${ }^{28}$

Podría argumentarse que en relación a los conflictos multiculturales, el fundamento personalista del derecho a no ser discriminado se limita a reconocer o proteger derechos individuales de los miembros de minorías y no a las minorías en cuanto grupos o colectivos. Efectivamente, desde esa perspectiva, a quienes se reconoce con propiedad en

26 http://www.derechoshumanos.net/Convenio-Europeo-de-Derechos-Humanos-CEDH/2000-Protocolo12ConvenioProteccionDerechosHumanosyLibertadesFundamentales.htm

${ }^{27}$ En este sentido BERNAL DEL CASTILLO, Jesús, La discriminación en el Derecho Penal, Granada: Ed. Comares, 1998, especialmente pp. 21-38. Ver también LAURENZO COPELLO, Patricia, "La discriminación en el Código Penal de 1995", Estudios Penales y Criminológicos” nº XIX (1996), pp. 219-288, p. 241.

${ }^{28} \mathrm{La}$ referencia a la dignidad de la persona permite también defender el derecho a la autodeterminación de la persona dentro de los grupos colectivos multiculturales, derecho que para algunos autores no estaba suficientemente claro en la construcción de los llamados derechos culturales colectivos; en este sentido, cita Raúl Carnevali el caso de la Comunidad Francófona de Quebec, con la pretensión de obligar a los niños de origen francés a que estudien en colegios donde se enseñara en esa lengua. CARNEVALI, "El multiculturalismo", cit. nota $\mathrm{n}^{\circ} 2$, p. 10. 


\section{Polít. crim. Vol. 9, № 18 (Diciembre 2014), Art. 3, pp. 371-399. [http://www.politicacriminal.cl/Vol_09/n_18/Vol9N18A3.pdf]}

un ordenamiento como sujetos del derecho a no ser discriminados son las personas físicas en virtud de unas características personales y de su integración o pertenencia a grupos o colectivos. En este sentido y en virtud del fundamento en la dignidad de la persona individual, no se atribuye directa y primariamente este derecho a los colectivos étnicos, nacionales, raciales, religiosos, etc. que generan la identidad o cualidad que es motivo del rechazo o discriminación. ${ }^{29}$

No obstante, desde una perspectiva axiológica, ${ }^{30}$ el principio de dignidad de la persona necesita a su vez del principio de sociabilidad del ser humano como ámbito de su desarrollo y, por ello, los valores jurídicos relacionados con las formas de integración social de la persona se convierten en condición y expresión necesarias de esa dignidad. A partir de esa dimensión social del principio de dignidad se fundamenta una Política Criminal tendente a la protección de bienes jurídicos colectivos y, en el tema que nos ocupa, se justifica la atribución de la condición de sujetos pasivos de los delitos discriminatorios a los colectivos o grupos como conjunto de todas aquellas personas que comparten una misma identidad por razones de su condición cultural, étnica, racial, etc., pudiendo también demandarse esa protección del grupo en sí mismo, cuando la conducta discriminatoria se dirija contra la colectividad en cuanto tal y no directamente a uno de sus miembros en cuanto sujeto directo de la ofensa. ${ }^{31}$

Aunque la dimensión colectiva del derecho a no ser discriminado está implícita en su contenido, no aparece siempre el grupo o minoría como objeto de protección penal en todos los delitos discriminatorios, sino solamente en aquellos en los cuales la conducta discriminatoria se hace extensiva o se dirige contra cualquier persona que pertenezca a un grupo racial, étnico o cualquier otro de los mencionados en las leyes. Esto tiene lugar especialmente en aquellos delitos relacionados con el llamado discurso del odio, que suponen un abuso de las libertades de expresión y opinión, o bien en la creación o pertenencia a las asociaciones u organizaciones cuyo fin sea la oposición y el rechazo de colectivos o minorías. En estos casos, sin perder de vista el fundamento personalista del derecho a no ser discriminado, la perspectiva colectiva de este derecho salta a primer plano en cuanto objeto de la protección penal, en concreto como lesión o amenaza al derecho a la integración de una persona (cualquiera) dentro de un colectivo o grupo determinado como medio de realización de su propia personalidad y de su propia identidad y como derecho de esos colectivos a la defensa de sus propias rasgos definitorios. En España esta dimensión

\footnotetext{
${ }^{29}$ Se puede argumentar que este planteamiento enlaza con el presupuesto liberal del no reconocimiento de derechos colectivos culturales sino sólo de derechos individuales culturales. En realidad, lo único que pretendo es situar éstos últimos como previos o fundamentadores de unos posibles derechos colectivos.

${ }^{30}$ El desarrollo de una Política Criminal fundada en principios normativos reviste un especial interés en nuestra argumentación; para un estudio en profundidad de esta construcción política criminal puede consultarse el Libro de SÁNCHEZ-OSTIZ GUTIÉRREZ, Pablo, Fundamentos de Política Criminal. Un retorno a los principios, Madrid: Marcial Pons, 2012.

${ }^{31}$ En este sentido es paradigmática la Sentencia del Tribunal Constitucional español 214/1991, de 11 de noviembre de 1991, que recoge un recurso de amparo a favor de una persona miembro del pueblo judío, que se vio afectada en su honor en cuanto a su pertenencia a dicho pueblo, por una entrevista donde se negaba el holocausto. Aunque se refiera al derecho al honor, esta sentencia recoge la dimensión colectiva de algunos derechos fundamentales especialmente vinculados a la dignidad de la persona y relacionados también con el derecho a no ser discriminado.
} 
BERNAL DEL CASTILLO, Jesús. "Política Criminal en España y discriminación xenófoba: la centralidad de los delitos de provocación a la discriminación".

colectiva del derecho a no ser discriminado y la protección directa de los grupos o colectivos en el Derecho Penal se reconoce en los delitos de provocación a discriminación, la violencia, al odio, las injurias discriminatorias, las asociaciones ilícitas de naturaleza xenófoba, la incitación al genocidio.

En cambio, en la tipificación de otros delitos discriminatorios la conducta lesiva se dirige directamente contra un sujeto determinado más que contra los grupos con el que se identifica y, en estos casos, la legitimación del grupo o colectivo para sentirse sujeto pasivo de ese delito, salvo expresa prescripción legal, queda en un plano secundario. Me refiero en concreto a los delitos que en el Derecho Penal español son calificados por la doctrina como directamente discriminatorios, como son la negación de prestaciones o servicios por razones discriminatorias, o bien el delito de discriminación laboral. Incluyo también en esta categoría la agravante por razones discriminatorias del art. 22.4ª del Código Penal español.

En cualquiera de los supuestos anteriores, el problema al que se enfrenta la Política Criminal antidiscriminatoria es su tendencia expansiva. Aunque en teoría el modelo político criminal propuesto sea más restrictivo que el modelo comunitario al no reconocer propiamente la existencia de derechos culturales, en la práctica la presión normativa internacional, especialmente en la Unión Europea, ${ }^{32}$ reclama una mayor intervención del Derecho Penal en algunos ámbitos de la discriminación, en concreto en la prevención del racismo y la xenofobia, con exigencias dirigidas a los países miembros ${ }^{33}$ para que lleven a cabo una reforma penal de sus legislaciones internas más exigente y extensiva, lo que implica una clara propuesta de criminalización del fenómeno discriminatorio.

Los efectos de una Política Criminal expansiva se pueden observar en algunos países europeos, especialmente en España, país donde vamos a centrar el resto de nuestro trabajo. El Código Penal español regula un numeroso grupo de delitos discriminatorios. No faltan razones para plantearse críticamente esta amplitud, tanto desde un punto de vista dogmático y sistemático, como desde la perspectiva de la oportunidad o necesidad de la tipificación de alguno de ellos para evitar un uso simbólico del Derecho Penal.

Desde la perspectiva dogmática penal, la doctrina española está de acuerdo en exigir que en la regulación de los diferentes tipos discriminatorios se respeten dos elementos esenciales: un injusto objetivo de cierta entidad y la existencia en el ámbito subjetivo de una razón o motivo de discriminación. ${ }^{34}$ Estas condiciones se deben concretar tanto si se trata de delitos que lesionan directamente derechos individuales como si se trata de delitos que protegen a los grupos o minorías y que adelantan la intervención penal definiendo la incitación o provocación a esas conductas discriminatorias. En el caso de la agravante discriminatoria,

\footnotetext{
32 Me refiero especialmente a la Decisión Marco 2008/913/JAI del Consejo, relativa la lucha contra determinadas formas y manifestaciones de racismo y xenofobia mediante el Derecho Penal, publicada en el Diario Oficial de la Unión Europea el 6.12.2008.

${ }^{33}$ Haciendo un amplio estudio de derecho comparado y exponiendo los distintos delitos antidiscriminatorios, vid. LANDA GOROSTIZA, Jon Mirena, La protección penal frente a la xenofobia., Bilbao: Universidad del País Vasco, 1999, especialmente pp. 103-203.

${ }^{34}$ Vid. la explicación de ambas condiciones en BERNAL DEL CASTILLO, La discriminación en el Derecho Penal, cit. nota ${ }^{\circ} 27$, pp. 31-48.
} 


\section{Polít. crim. Vol. 9, Nº 18 (Diciembre 2014), Art. 3, pp. 371-399. \\ [http://www.politicacriminal.cl/Vol_09/n_18/Vol9N18A3.pdf]}

se puede considerar que se justifica el fundamento agravatorio de otro delito cuando concurre alguna de las motivaciones del artículo $22.4^{\text {a }}$ del Código Penal. ${ }^{35}$

La perspectiva político criminal plantea también otras consideraciones sobre la necesidad de la tipificación de los diferentes delitos discriminatorios y su eficacia. Se trata de una cuestión compleja, en cuanto exige valorar cuestiones de diferente naturaleza: por ejemplo, la realidad de la inaplicación de muchos de esos tipos penales por los tribunales, ${ }^{36}$ la posibilidad de prevenir en la realidad social concreta la discriminación con medidas sociales y políticas previas al recurso al ordenamiento penal, etc. También entra en consideración la necesidad de hacer frente a nuevas formas de discriminación, que quizás no encuentran acomodo en los tipos penales ya consolidados o que reclaman la reforma de los mismos.

Ante la imposibilidad de desarrollar todas las cuestiones anteriores, considero de especial interés referirme a la conducta que podemos denominar en términos generales de incitación y provocación a la discriminación, que ocupa una posición central en la Política Criminal internacional contra la discriminación punible. En particular, el estudio de este delito en la normativa española permite plantear algunos de los problemas relevantes a los que me he referido anteriormente: la justificación de una Política Criminal expansiva, el objeto de protección de los delitos contra la discriminación, la delimitación de los elementos objetivos y subjetivos de los delitos discriminatorios y, finalmente, el problema de los conflictos entre la interdicción de la discriminación y el ejercicio de otros derechos fundamentales, sobre todo el derecho a la libertad de expresión.

\section{La centralidad del delito a la provocación al racismo, al odio y a la violencia}

Al igual que otros delitos que afectan directamente al problema de la discriminación, el Código Penal español tipifica la provocación, al odio y a la violencia en la sección $1^{\mathrm{a}}$, del Capítulo IV, del Título XXI, Libro II, bajo la rúbrica "De los delitos cometidos con ocasión del ejercicio de los derechos fundamentales y de las libertades públicas, garantizados por la Constitución". Esta sistemática es correcta teniendo en cuenta la fundamentación axiológica que hemos hecho del derecho a no ser discriminado como derivación de la dignidad de la persona y en el desarrollo de su personalidad. ${ }^{37}$

\footnotetext{
${ }^{35}$ Sobre las distintas orientaciones respecto a la fundamentación de la agravante discriminatoria ver el trabajo de DOPICO GÓMEZ-ALLER, Jacobo, "Delitos cometidos por motivos discriminatorios: una aproximación desde los criterios de legitimación de la pena", Anuario de Derecho Penal y Ciencias Penales, tomo LVII (2004), pp. 143-175.

${ }^{36}$ Esta cuestión ha sido estudiada en España entre otros autores por LANDA GOROSTIZA, Jon Mirena, en relación al delito de incitación a la discriminación, al odio o a la violencia, especialmente en su artículo "Incitación al odio: evolución jurisprudencial (1995-2011) del art. 510 CP y propuesta de lege lata", Revista de Derecho Penal y Criminología, n 7 (2012), pp. 297-346; y también por TAPIA BALLESTEROS en relación al delito del artículo 314 del Código Penal español, en La discriminación laboral, cit. nota $\mathrm{n}^{\circ} 25$, pp. 348-355.

${ }^{37}$ Fuera de esta sección el código penal español regula otros delitos directamente discriminatorios, bien por razones de especialidad, como el delito de discriminación laboral; o bien porque el hecho discriminatorio se protege de forma indirecta o instrumental como sucede en la negación o apología del genocidio.
} 
BERNAL DEL CASTILLO, Jesús. "Política Criminal en España y discriminación xenófoba: la centralidad de los delitos de provocación a la discriminación”.

El artículo 510 del Código Penal español en su redacción actual regula dos delitos discriminatorios diferentes, pero agrupados en un mismo precepto por razón de su naturaleza como delitos de opinión. En efecto tanto la provocación a la discriminación (art. 510.1) como las injurias discriminatorias (art. 510.2) se pueden considerar atentados contra el derecho a no ser discriminado realizados con ocasión del ejercicio de los derechos a la libertad de expresión y de información, constituyendo extralimitaciones de estos derechos. Una de las diferencias entre ambos delitos radica en que mientras las injurias discriminatorias implican una lesión directa del derecho a no ser discriminado, en concreto porque expresan un desprecio fundado en razones discriminatorias, la provocación a la discriminación se mantiene en un plano anterior, ya que constituye una incitación para realizar futuros actos discriminatorios, en cuanto impiden u obstaculizan el ejercicio de derechos.

La tipificación de hechos que todavía no son propiamente discriminatorios, como sucede en este delito de provocación, plantea especialmente la necesidad de justificar esa anticipación del recurso del Derecho Penal.

Desde una perspectiva político criminal se alegan motivos sociales para considerar el llamado discurso del odio "hate speech" como el núcleo central de la actual política antidiscriminatoria en Europa, que impulsa en lo posible unos mínimos punibles en esta materia comunes a los Estados miembros. Sin desconocer que los actos violentos por razones racistas o discriminatorias son una triste realidad, con brotes periódicos en diversos países, hay que plantearse que precisamente la violencia y discriminación directa surge, en gran medida, a través de un clima de opinión que se puede materializar en la incitación al odio racista o xenófobo. La potencial peligrosidad para generar conflictos sociales violentos con origen en la ideología extremista discriminatoria es visible especialmente en las sociedades europeas, donde la inmigración masiva y la falta de integración de esos inmigrantes ha despertado en ciertos sectores radicales nuevas formas de rechazo a nivel político y social de estos colectivos o ha resucitado viejos prejuicios y opiniones contra colectivos que históricamente han sido víctimas de un trato discriminatorio.

Debido a la facilidad de la transmisión de esas ideas y opiniones de contenido xenófobo o racista a través de los avances de las nuevas tecnologías, la peligrosidad de los actos de comunicación que incitan o propagan esas ideas, con fundamento en una ideología contraria a la dignidad de la persona, constituye un problema que exige una especial atención preventiva, considerándose adecuado el recurso al Derecho Penal cuando la transmisión, comunicación o exposición de ideas racistas, xenófobas o discriminatorias, reúna suficientes elementos de gravedad ${ }^{38}$ para entender no sólo que se han cruzado las

\footnotetext{
${ }^{38} \mathrm{La}$ aparición de actitudes discriminatorias en España que tienen una especial gravedad y que por ello son penalmente relevantes, se ha puesto de manifiesto en hechos que responden precisamente a la distribución de material bibliográfico racista, la difusión de programas políticos, la formación de asociaciones ideológicas antisemitas y xenófobas, etc., que son precisamente las cuestiones que han llegado a los tribunales. Una visión conjunta de las resoluciones más importantes en España sobre estas cuestiones puede verse en CUEVA FERNÁNDEZ, Ricardo, “A propósito de la Sentencia del Tribunal Supremo 259/2011: Discurso del odio, incitación y derecho al honor colectivo. ¿Una nueva vuelta de tuerca contra la prohibición del hate speech?”, Eunomia. Revista en Cultura de la Legalidad, n 2 (2012), pp. 99-108; http://eunomia.tirant.com/?p=963, [visitado 25.03.2014]. Ver también el trabajo de LANDA GOROSTIZA, "Incitación al odio", cit. nota n 36.
} 
fronteras del ejercicio legítimo de las libertades ideológica, de opinión y de expresión, sino que se puede legitimar la tipificación de dichas conductas.

A estas causas obedece, como he señalado anteriormente, que la tipificación de estos delitos haya formado parte del núcleo duro de la normativa internacional antidiscriminatoria en Europa a partir de la Segunda Guerra Mundial, secundando de esta forma la normativa de los organismos internacionales (véase especialmente el artículo 4 de la Convención para la eliminación de todas las formas de discriminación racial de 1965). ${ }^{39}$ En particular, la ratificación de este Convenio por España es el origen de la tipificación del artículo 510.1 del Código Penal español.

La Política Criminal de la Unión Europea actualiza también esta misma orientación, proponiendo a todos los países miembros una tipificación penal de los delitos de incitación y provocación al racismo y a la xenofobia como una de las formas graves de racismo y discriminación que merece y debe ser penalmente tipificada; así lo expresa el artículo 1 de la Decisión Marco del Consejo 2008/913, el cual se cita expresamente en el nuevo Proyecto de Reforma del Código Penal español para consolidar y reforzar el vigente artículo $510 .^{40}$

De este marco general europeo se diferencian otros países, especialmente Estados Unidos. Las singularidades de la evolución de la lucha contra la discriminación y el racismo en este país, ${ }^{41}$ han impedido que en el Derecho Penal norteamericano se configure la provocación xenófoba, por razones que tienen que ver con el carácter expansivo de la libertad de expresión. En cambio, sigue la tendencia general europea el Reino Unido, que tipifica la provocación en la Public Order Act, sección 18, de 1986, por lo que no podemos hablar de un modelo antidiscriminatorio anglosajón único ni tampoco en este caso opuesto al modelo europeo continental.

\section{3. ¿A quiénes protege el delito de provocación a la discriminación?}

Si bien parece clara la centralidad de la incitación al racismo y a la xenofobia dentro de la normativa penal antidiscriminatoria, se plantean en torno a este delito diversas cuestiones críticas y problemáticas en torno a su naturaleza y delimitación de sus elementos, porque sobre él, al menos entre algunos autores, pesa la idea de que nos encontramos por su deficiente configuración, ante un delito "simbólico" $o$, al menos, insuficientemente fundamentado en su regulación actual. ${ }^{42}$

\footnotetext{
${ }^{39}$ Ver el estudio de derecho comparado que hace LANDA GOROSTIZA, La protección penal frente a la xenofobia, cit. nota $\mathrm{n}^{\mathrm{o}} 33$, p. 204.

${ }^{40}$ Literalmente, el artículo 1, a) de la Decisión Marco de 2008 expresa: “1. Cada Estado miembro adoptará las medidas necesarias para garantizar que se castiguen las siguientes conductas intencionadas: a) la incitación pública a la violencia o al odio dirigidos contra un grupo de personas o un miembro de tal grupo, definido en relación con la raza, el color, la religión, la ascendencia o el origen nacional o étnico".

${ }^{41}$ Una exposición breve pero clara de la evolución de la lucha contra el racismo en Estados Unidos puede verse en JOPKE, "Minority Rights", cit. nota n 4, pp.57-59.

${ }^{42}$ Así piensa, por ejemplo, BENLLOCH PETIT, Guillermo, "El Derecho Penal ante el conflicto político: Reflexiones en torno a la relevancia penal de determinados fines, opiniones o motivos políticos o ideológicos y su legitimidad", Anuario de Derecho Penal y Ciencias Penales, t. 54 (2001), pp. 175-227, p. 197, y especialmente LANDA GOROSTIZA en varios de sus trabajos. Este autor argumenta en particular las
} 
BERNAL DEL CASTILLO, Jesús. "Política Criminal en España y discriminación xenófoba: la centralidad de los delitos de provocación a la discriminación".

El primer ámbito de discusión radica en la identificación tanto del bien jurídico protegido como de los sujetos titulares del mismo. Esta cuestión permitirá concretar si encontramos un fundamento válido para defender la legitimidad de la intervención penal en este delito.

En el caso particular de la provocación al racismo y a la discriminación, aparecen como sujetos pasivos directamente afectados por este delito, determinados grupos o asociaciones. Esta mención expresa que hace el artículo 510. 1 del Código español no invalida la argumentación que expuse previamente defendiendo que todo delito discriminatorio manifiesta de un modo particular una vulneración del derecho a no ser discriminado y su fundamento en la dignidad de la persona.

En el delito de provocación la lesión de la dignidad de cada individuo adquiere un matiz especial relacionado con los sujetos pasivos del delito. La actuación provocadora se realiza a través de la difusión pública y esta definición del delito extiende el alcance de la afectación de la dignidad y de los derechos fundamentales más allá de los sujetos individuales, en concreto a los grupos o asociaciones caracterizados por las circunstancias que expresa literalmente el artículo 510.1. Ello implica superar la individualidad del sujeto pasivo del delito para definir que cualquier persona que comparta una misma identidad por razones de su condición cultural, étnica, racial, etc. será automáticamente considerada sujeto pasivo de este delito, lo cual resulta coherente con la análoga resolución que se ha dado a la llamada mentira de Auschwitz, que propiamente debe calificarse, en mi opinión, bien como un caso de injurias discriminatorias bien como un supuesto de enaltecimiento del genocidio.

Esta consideración sobre los sujetos pasivos conduce a una segunda cuestión. En concreto, si el delito de provocación del artículo 510.1 tiene como sujeto pasivo no solamente a la suma numérica de los individuos que pertenecen a un grupo o colectivo determinado, sino al grupo o colectividad en cuanto tal, con independencia de sus miembros individuales.

Debemos recordar que el fundamento de la peligrosidad de la provocación se encuentra realmente en que se trata de una conducta cuyo objetivo es crear un clima de violencia o rechazo contra toda persona que forme parte de un grupo o colectividad, y que son los elementos comunes diferenciales de esta colectividad los que constituyen el objeto de la animosidad de los autores de los actos de incitación. A partir de aquí la doctrina española hace diversos matices. ${ }^{43}$ Algunos autores defienden que el delito de provocación a la discriminación pretende la protección de colectividades o minorías en cuanto dan unidad a la personalidad de los sujetos que se agrupan o definen con base en dichos grupos y, tomando como referencia el tenor literal del art. 510.1, excluyen de este delito como sujetos pasivos a los miembros individuales de los grupos. ${ }^{44}$

razones de la escasa aplicabilidad de este delito por la jurisprudencia en su artículo ya citado "Incitación al odio", cit. nota n 36 .

${ }^{43}$ Sobre este tema puede consultarse RODRÍGUEZ YAGÜE, Cristina, "Una propuesta de clasificación de los delitos de discriminación en el Código Penal español", Publicaciones del Instituto de Derecho Penal Europeo e Internacional, dos mil-tres mil, 2007, Universidad de Castilla La Mancha no 11, pp. 1-25, pp.11-18.

44 Ver entre otros CANCIO MELIA, Manuel, en: JORGE BARREIRO, Agustín, RODRÍGUEZ MOURULlO, Gonzalo (coords.), Comentarios al Código Penal, Madrid: Ed. Cívitas, 1997, pp. 1272- 1337, p. 1275. 
Personalmente no comparto dicha exclusión. Es cierto que la protección de colectividades no es ninguna novedad en el Derecho Penal, ni tampoco el reconocimiento de bienes jurídicos que posea el grupo con independencia de sus miembros. Pero creo que ello no es aplicable al delito de provocación a la discriminación, al odio o a la violencia. La defensa de estos colectivos se articula más bien como defensa de la totalidad de los miembros que los componen, de forma que la provocación amenaza a cualquiera de ellos.

En mi opinión, la actual redacción del artículo 510.1, que castiga a "los que provocaren a la discriminación, al odio o a la violencia contra grupos o asociaciones....", debe interpretarse efectivamente como un delito contra esas colectividades, pero con el matiz de que los grupos no son titulares de derechos culturales propios. Una interpretación de esta naturaleza resultaría un poco forzada, pues llevaría a entender que el bien jurídico protegido en el delito de provocación a la discriminación, al odio o al a violencia son precisamente los derechos culturales cuya titularidad ostentarían los grupos o colectivos respectivos y no la seguridad o la dignidad de todos miembros de las minorías.

Más bien, entiendo desde la perspectiva personalista que fundamenta la lucha antidiscriminatoria en el ámbito del Derecho Penal, que el delito de provocación contra las minorías es punible en cuanto que la incitación a la violencia o al odio afecta objetivamente a todos y cada uno de los miembros de dicha colectividad por el hecho de su pertenencia a la misma. De aquí se deduce que las expresiones que designan a los sujetos pasivos en estos delitos: grupos y asociaciones, expresan y representan al conjunto completo de las personas que en ellos se incluyen. Por esta razón, se puede hablar propiamente de que la provocación discriminatoria se dirige contra los grupos culturales, étnicos o religiosos como sujetos pasivos de los delitos de discriminación en cuanto son depositarios y generadores de aquellos elementos propios de ese grupo que conforman la personalidad y derechos de sus miembros.

La consideración de la peligrosidad del delito de provocación a la discriminación, odio y violencia en cuanto se dirige a grupos enteros o a sus miembros se ve reforzada por la moderna Política Criminal de la Unión Europea, en concreto en la Decisión Marco, ya citada, donde tras señalar que el racismo y la xenofobia deben ser considerados como una violación directa de los derechos fundamentales, exige la tipificación, entre otros delitos, de la incitación pública a la violencia y al odio cuando van dirigidos contra un grupo de personas o un miembro de tal grupo. En España, siguiendo esta indicación, el nuevo proyecto de reforma del Código Penal, actualmente en trámite parlamentario, considera como sujetos pasivos de las distintas figuras que contempla el artículo 510.1:

“a un grupo, una parte del mismo o contra una persona determinada por razón de su pertenencia a aquél”.

Esta doble perspectiva, individual y colectiva, de los sujetos pasivos ${ }^{45}$ no es incompatible con un planteamiento restrictivo del delito de provocación. Preocupado por evitar la

\footnotetext{
${ }^{45}$ En el sentido que propongo puede citarse como norma de referencia, el artículo 130 del Código Penal alemán, tanto en el número (1), como en el número (2), que se refiere propiamente al mismo delito de
} 
BERNAL DEL CASTILLO, Jesús. "Política Criminal en España y discriminación xenófoba: la centralidad de los delitos de provocación a la discriminación".

tendencia expansiva de este delito, Landa Gorostiza ${ }^{46}$ defiende la aplicación restrictiva del ámbito típico limitando el ámbito de los sujetos pasivos a aquellos grupos o colectivos especialmente vulnerables que serían aquellos que se encuentran en una situación crítica en términos de existencia o de debilidad.

Es difícil justificar esta limitación cuando no puede deducirse del texto del tipo penal; en el artículo 510.1 las condiciones requeridas a los sujetos pasivos son la pertenencia a una minoría caracterizada por alguna de las circunstancias enumeradas en el tipo, sin tener en cuenta la fragilidad de la posición social del grupo. La gravedad del injusto depende de la peligrosidad de la incitación en términos de generar la posibilidad de actos de violencia o de odio. Sin embargo, la idea limitadora de la aplicación de este tipo penal resulta interesante, pero debe venir por una interpretación estricta del concepto de provocación en términos de posibilidad de generar violencia y, desde el punto de vista de los sujetos pasivos, por una identificación de los colectivos o grupos amenazados con aquellos que realmente se caracterizan por una condición de diferenciación cultural, cuestiones ambas que se expondrán en el siguiente apartado.

Queda resolver un segundo problema en relación a los sujetos pasivos y al bien jurídico protegido del delito del artículo 510.1. Si la perspectiva comunitaria considera en un primer plano la seguridad de estos colectivos y los derechos de las personas que los componen a afectos de definir el fin de la norma penal, entonces se puede entender que consecuentemente se protege también en la misma, como bien jurídico adicional, la paz y el orden público en general, ${ }^{47}$ en cuanto ambos se pueden ver afectados por la incitación a la violencia y discriminación contra una parte de la sociedad. Incluso avanzado en esta interpretación, podría advertirse en la tipificación de este delito un ataque directo a la configuración democrática y plural del Estado.

Desde un punto de vista político criminal, la distorsión e inestabilidad social causada por los delitos de odio y, en concreto, por la incitación a la violencia y al odio, son un elemento más de la peligrosidad de esta conducta y permiten fundamentar la gravedad del injusto objetivo, justificando el adelanto de la intervención penal a este tipo de conductas de provocación como parte de la moderna política antidiscriminatoria. ${ }^{48}$ No obstante, la evitación del peligro contra el orden público y la paz social no puede convertirse en el bien jurídico principal que justifique la tipificación de la incitación o provocación a las minorías, por delante de los derechos de los grupos y colectivos y de sus miembros, hasta el punto de que pueda condicionarse la tipificación de este delito en la medida en que cause graves

incitación. En la definición de este delito el código alemán considera como sujetos pasivos a individuos concretos, partes de la población, grupos o partes de grupos, etc.

${ }^{46}$ LANDA GOROSTIZA, La protección penal frente a la xenofobia, cit. nota no 33, pp. 388 y 389.

${ }^{47}$ Patricia Laurenzo configura como segundo bien jurídico protegido por estos tipos penales el modelo de convivencia plural y multicultural trazado por la Constitución, garante de las ideas de pluralismo, tolerancia y respeto a las diferencias, bien jurídico de corte colectivo afectado igualmente por las conductas de discriminación. LAURENZO COPELLO, "La discriminación en el Código penal de 1995”, cit. nota n 27, p. 241.

${ }^{48}$ Así lo afirma LANDA GOROSTIZA respecto a Alemania, Suiza, Austria o Gran Bretaña, en La protección

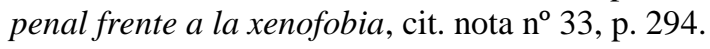




\section{Polít. crim. Vol. 9, Nº 18 (Diciembre 2014), Art. 3, pp. 371-399. [http://www.politicacriminal.cl/Vol_09/n_18/Vol9N18A3.pdf]}

daños a la paz social y al Estado. ${ }^{49}$ En ambos casos perderíamos de vista la interdicción de la discriminación como defensa de grupos o minorías y lo convertiríamos en uno más de los delitos contra la seguridad del Estado, lo cual no puede deducirse de la orientación político criminal que venimos defendiendo.

\section{Los elementos objetivos y subjetivos del injusto de la provocación a la discriminación}

En el apartado anterior he defendido la orientación político criminal que tipifica la provocación dirigida a la comisión de actos de violencia o rechazo de personas por su pertenencia a un grupo determinado. La peligrosidad de estas conductas constituye el fundamento de esta Política Criminal común en el ámbito de las sociedades occidentales. A cada Estado queda la tarea de concretar, dentro del marco general señalado por las normas internacionales, la definición y los elementos de este delito.

No resulta una tarea fácil, dado que estamos en el ámbito de los delitos de opinión y que además, se está anticipando la intervención del Derecho Penal a conductas previas a la comisión de los actos propiamente xenófobos, racistas o violentos. Por ello, debe exigirse la tipificación de este delito conforme a unos elementos objetivos y subjetivos que expresen con claridad una gravedad de las conductas suficiente para poder calificar las expresiones u opiniones no sólo como manifestaciones ilegítimas de la libertad de expresión desde un punto de vista ético-social, sino como hechos merecedores de una prevención jurídica anticipada concretada en la aplicación de una sanción penal. ${ }^{50}$

A este respecto la regulación de este delito en España ha sido objeto de críticas, centradas especialmente en su naturaleza como delito de peligro abstracto y en la deficiente delimitación de las conductas típicas. Éstas se definen efectivamente de un modo inconcreto y genérico como provocar a la discriminación, al odio y a la violencia contra grupos o asociaciones, cuando son realizadas por los motivos que se enuncian en el artículo 510.1:

"Los que provocaren a la discriminación, al odio o a la violencia contra grupos o asociaciones, por motivos racistas, antisemitas u otros referentes a la ideología, religión o creencias, situación familiar, la pertenencia de sus miembros a una etnia o raza, su origen nacional, su sexo, orientación sexual, enfermedad o minusvalía, serán castigados con la pena de prisión de uno a tres años y multa de seis a doce meses."

\footnotetext{
${ }^{49}$ Veo esta intención en la disposición del artículo 1, apartado 2, de la Decisión Marco del Consejo de 2008, donde se expresa que, respecto a las conductas que deben ser tipificadas por los distintos países, relacionadas con la incitación, enaltecimiento, etc. del racismo y xenofobia, se puede limitar la tipificación de alguna de ellas a aquellas que "o bien se lleven a cabo de forma que puedan dar lugar a perturbaciones del orden público o que sean amenazadoras, abusivas o insultantes".

50 En un delito próximo a la discriminación, en concreto respecto al delito de genocidio, el Tribunal Constitucional español calificó como una invasión no justificada del Derecho Penal en ámbitos propios de la libertad de expresión, la simple negación del genocidio definida en el art. 607.2 (Sentencia del Tribunal Constitucional Español 235/2007). De ahí la necesidad de delimitar bien la peligrosidad para el bien jurídico protegido de las conductas que expresan opiniones o valoraciones discriminatorias sobre otras personas o sobre grupos minoritarios.
} 
BERNAL DEL CASTILLO, Jesús. "Política Criminal en España y discriminación xenófoba: la centralidad de los delitos de provocación a la discriminación".

La indeterminación legal del concepto de provocación en este delito constituye efectivamente un problema para determinar la gravedad de dicha conducta en relación a la puesta en peligro del bien jurídico: la protección de las minorías en el sentido de no ser objeto de actos de discriminación, violencia u odio.

Esta deficiencia se ha soslayado haciendo una interpretación del concepto de provocación que se remite al concepto general de provocación como acto preparatorio del delito en el artículo 18 del Código Penal, ${ }^{51}$ de forma que lo que se prohíbe es una "incitación pública directa" a la comisión de un delito particular, hecha por medios que expresen la eficacia virtual de esa comunicación para que otros realicen el hecho al que se incita En este sentido se ha pronunciado el Tribunal Supremo español en la sentencia 259/2011, de 12 de abril, sala $2^{a}$ (librería Kalki). Aunque esta interpretación garantice la real peligrosidad de la conducta de provocación a la discriminación, al exigir que la provocación consista en una incitación directa y eficaz a la comisión de un delito, también puede dar lugar también a una aplicación restrictiva del mismo, problema que no han dejado de señalar algunos autores españoles. ${ }^{52}$

En mi opinión, la conexión entre el concepto de provocación a la discriminación y el concepto general de provocación del artículo 18 del Código Penal me parece correcta como criterio general de interpretación. No obstante entiendo que en el delito de provocación a la discriminación concurren características especiales que permiten una referencia real pero atenuada, o si se quiere matizada, a los requisitos tan estrictos que se exponen en el artículo 18. También el propio Tribunal Supremo español, en la citada sentencia de 2011, parece que sigue esta línea interpretativa cuando dice dicha remisión se refiere a una "incitación directa a la comisión de hechos mínimamente conectados con los requisitos del artículo 18". Abundando en este sentido, Landa Gorostiza ${ }^{53}$ expone que el Tribunal Supremo se adhiere a una concepción de la provocación tributaria sólo en parte de las características atribuibles a la definición del artículo 18.

Por mi parte no creo que el concepto de provocación del artículo 510.1 deba comprender solamente la incitación a la comisión de hechos delictivos, entendiendo por tales los delitos tipificados en el Código Penal. Cabe otra interpretación diferente fundada en la orientación político criminal defendida en este trabajo y que sitúa el objetivo de la lucha antidiscriminatoria en la aceptación de personas integrantes de minorías y el reconocimiento de los derechos comunes a todos los sujetos que habitan en un Estado, con independencia de sus características culturales.

Desde esta perspectiva, se reconoce que las medidas antidiscriminatorias estatales abarcan en los diferentes ámbitos jurídicos todo tipo de conductas de rechazo o de creación de un

\footnotetext{
${ }^{51}$ Artículo 18.1: "La provocación existe cuando directamente se incite por medio de la imprenta, la radiodifusión o cualquier otro medio de eficacia semejante, que facilite la publicidad, o ante una concurrencia de personas a la perpetración de un delito".

${ }^{52}$ Así lo expone GARCÍA ÁLVAREZ, Pastora, El derecho Penal y la discriminación. Especial referencia al extranjero como víctima de discriminaciones penalmente relevantes, Valencia: Tirant Lo Blanch, 2004, pp. 243 y ss.

${ }^{53}$ LANDA GOROSTIZA, “Incitación al odio” cit. nota nº 36, especialmente pp. 315 y 316.
} 
clima contrario a la integración, incluso aquellas que tienen escasa entidad. En cambio, la naturaleza subsidiaria del Derecho Penal exige tipificar únicamente los comportamientos discriminatorios más graves, lo que podría llevar a la conclusión respecto a la provocación discriminatoria, que los actos de expresión o incitación punibles deben dirigirse efectivamente a la incitación de "hechos delictivos". Pero entiendo que, junto al concepto jurídico positivo de delito, también posee la misma o parecida gravedad la incitación a realizar comportamientos que, sin estar tipificados como infracciones penales, realmente implican la negación de derechos que son fundamentales para la persona: sustento, vivienda, acceso a la salud, etc., o de aquellos otros que se consideran necesarios para la integración de una persona en un nuevo país: negación del acceso a determinados lugares, discriminación en las escuelas, prohibición de mostrar símbolos religiosos, etc., porque también estas conductas desde el punto de vista de su gravedad lesionan tanto la dignidad de la persona como su identidad cultural.

En este sentido, cuando esas conductas discriminatorias consisten en la incitación pública contra los grupos o colectividades minoritarios, podría interpretarse el requisito exigido por el Tribunal Supremo español de referir el concepto de provocación al artículo 18 del Código Penal en un sentido más amplio que el de incitar de incitar a la comisión de hechos formalmente tipificados como delitos. ${ }^{54} \mathrm{La}$ provocación al odio, violencia o a la discriminación se puede referir en concreto a la incitación para realizar otro tipo de actos que por su gravedad se pueden considerar próximos a lo delictivo o sean susceptibles de serlo por afectar a derechos fundamentales de la persona y a las exigencias necesarias para la integración o aceptación de los grupos minoritarios o de sus miembros y que, en el contexto en que se producen, reúnan cierta entidad o idoneidad para ello. ${ }^{55}$

En segundo lugar, el requisito de que la provocación sea directa y realizada públicamente o por medios de difusión eficaz es una de las condiciones que se alegan para determinar la peligrosidad de las conductas de provocación del artículo 510. En este ámbito me planteo la posibilidad de admitir como conducta típica no sólo la incitación directa a la discriminación, sino también la llamada incitación indirecta.

El concepto de provocación directa debe entenderse como aquella forma de comunicación cuyo fin es promover la realización de hechos determinados caracterizados como actos de discriminación de odio o de violencia. Este concepto aparece también legalmente concretado por la indeterminación de los sujetos a quienes se dirigen las expresiones o mensajes con contenido discriminatorio.

En el derecho comparado se utilizan conceptos diferentes a la hora de definir la provocación. La palabra provocación o incitación no es la única empleada, añadiéndose otras expresiones que tienen un significado similar o complementario al de provocar o

\footnotetext{
${ }^{54}$ Así opinó en su día LAURENZO COPELLO, Patricia, "Marco de protección jurídico-penal del derecho a no ser discriminado. Racismo y xenofobia", Cuadernos de Derecho Judicial, nº 1 (1996), pp. 217-242, p. 253 y ss.

${ }^{55}$ La enumeración constitucional de los derechos fundamentales de la persona y los derechos de los ciudadanos podrían servir de marco referencial a efectos del delito de provocación a la discriminación, odio o violencia.
} 
BERNAL DEL CASTILLO, Jesús. "Política Criminal en España y discriminación xenófoba: la centralidad de los delitos de provocación a la discriminación”.

incitar. Por ejemplo en el parágrafo 130 del Código Penal alemán aparece con claridad que la conducta típica se refiere a actos dirigidos a la incitación de personas, y también se determina que se trata de una incitación dirigida a grupos indeterminados, requiriéndose como expone Albin Eser ${ }^{56}$ la naturaleza pública del acto de incitación. Para Eser se justifica este delito porque la persona que incita a la comisión de esos actos pierde el control de sus palabras o escritos, de forma que puede causar un daño desconocido. En esa pérdida del control del resultado de la incitación, causada por la publicidad del mensaje, se observa precisamente la peligrosidad de estas conductas, siempre y cuando la incitación implique una cierta concreción de los actos incitados y resulte idónea para ello.

Sobre la aceptación de la incitación indirecta, en mi opinión debe admitirse tal concepto cuando se pone en relación con los medios de transmisión del mensaje provocador y, en concreto, porque así lo permite el requisito de la publicidad de la incitación y la difusión de la misma, que es donde realmente radica la realidad de la peligrosidad de los delitos de opinión.

La incitación será ciertamente punible cuando el mensaje provocador se transmite con total claridad y precisando el hecho o hechos que se persiguen. Pero el uso de la palabra, oral o escrita y, en especial, la utilización de los modernos medios de comunicación y las nuevas tecnologías, permiten hacer una interpretación progresiva del concepto de incitación, para acoger en este supuesto diferentes formas de difusión de ideas o mensajes cuyo contenido provocador puede quedar difuminado o encubierto por la peculiar naturaleza de estos medios de comunicación. Se puede poner como ejemplo el envío de un whatsapp o un Tweet, que pueden expresar en una sola frase un mensaje que llega a muchas personas y que, por su excesiva simplicidad o brevedad, pudieran no entenderse como directamente incitadores, cuando en realidad tienen una eficacia tremenda en cuanto a sus efectos sociales: movilizaciones de grandes masas, cascada de mensajes, etc. De igual forma, una caricatura publicada en un periódico puede tener un verdadero contenido provocador, dado que aunque se exprese por medio del dibujo, éste puede tener un significado simbólico y, al mismo tiempo, un mensaje claramente incitador. Por estas razones, al menos en España, se ha aceptado en varias resoluciones judiciales la utilización de estas nuevas formas de comunicación, en concreto el uso de páginas web, como medios de comisión de este delito de provocación. ${ }^{57}$

De estas consideraciones se puede manifestar que la extensión del concepto de provocación indirecta defendida en torno al elemento de la extensión de la difusión del mensaje es una posibilidad que debe ser tomada en consideración, tal y como hacen ya los tribunales en España, ${ }^{58}$ criterio con el que estoy personalmente de acuerdo por adecuarse a la ratio legis

\footnotetext{
${ }^{56}$ ESER, Albin, "The law of Incitement and the use of speech to incite others to commit Criminal Acts: German Law in Comparative Perspective", en: KRETZMER, David; KERSHMANN, Francine (dirs.) Freedom of speech and Incitement Against Democracy, The Hague: Kluwer Law International Ed., 2000, pp. 119-145, p. 126.

${ }^{57}$ Sentencia del Juzgado de lo penal de Lleida, de 16 de noviembre de 2006 y Sentencia del Juzgado de lo Penal de Barcelona, de 16 de junio de 2010.

${ }^{58}$ Así lo afirma LANDA GOROSTIZA, sobre todo cuando analiza la jurisprudencia española a la hora de diferenciar entre el delito de incitación al genocidio del artículo 607.2 con el delito del artículo 510.1. Ver "Incitación al odio", cit., nota n ${ }^{0}$ 36, pp. 317-319. Más en concreto, la Sentencia del Tribunal Supremo
} 
Polít. crim. Vol. 9, № 18 (Diciembre 2014), Art. 3, pp. 371-399.

[http://www.politicacriminal.cl/Vol_09/n_18/Vol9N18A3.pdf]

del artículo 510.1 del Código Penal, que pretende fundamentar suficientemente un injusto de peligrosidad abstracta próxima al peligro concreto.

Desde el punto de vista práctico, a la hora de entender con amplitud el concepto de provocación, deben tenerse en cuenta los posibles conflictos con las libertades de expresión, ideológica $\mathrm{y}$, dado que hablamos del uso de nuevas tecnologías, también del secreto a las comunicaciones. Por eso resulta inevitable la necesidad de realizar en cada caso concreto donde se plantee ese conflicto, un juicio de ponderación entre los mensajes provocadores difundidos "indirectamente" respecto del contenido esencial del ejercicio legítimo de la libertad de expresión. En este juicio de ponderación, además de valorar el contenido del mensaje y el medio de su transmisión, no debe olvidarse la perspectiva político criminal actual dirigida a garantizar una protección más eficaz contra la discriminación, criterio axiológico que permite aceptar que se ha realizado el injusto propio del artículo 510.1 en los casos en que, aunque no se especifique literalmente el delito o la acción antixenófoba o discriminatoria, quede suficientemente claro por el sentido del mensaje, el texto o el alcance del medio de difusión, la voluntad de provocar acciones colectivas graves en dicho sentido.

Finalmente debe hacerse referencia al último elemento del injusto: las causas o razones discriminatorias, requisito explícitamente exigido en dicho precepto y que debe ser interpretado como un elemento estrictamente subjetivo del tipo de los delitos discriminatorios distinto del dolo. ${ }^{59}$ En efecto, el dolo en su forma directa se presupone en cuanto la descripción de este delito se define como "incitación". Las causas o razones discriminatorias, aunque fundamentan el dolo, constituyen un elemento diferente, necesario para apreciar el injusto, en cuanto expresan no sólo la actitud del sujeto activo hacia las condiciones objetivas de raza, etnia, etc., sino las circunstancias o cualidades que concurren en el sujeto pasivo y que originan esta actitud de rechazo en el sujeto activo.

Interpretado en este sentido, la crítica que se puede hacer a este requisito subjetivo recae en primer lugar en la falta de necesidad de su enumeración exhaustiva:

"por motivos racistas, antisemitas u otros referentes a la ideología, religión o creencias, situación familiar, la pertenencia de sus miembros a una etnia o raza, su origen nacional, su sexo, orientación sexual, enfermedad o minusvalía”.

Soy contrario a mantener tal enumeración por un doble motivo; el primero y más importante es que muchas de esas circunstancias no obedecen a la ratio legis del precepto, que es la protección de la integración de minorías caracterizadas por distintivos relacionados con la multiculturalidad. El delito del artículo 510.1 protege a las personas del derecho a no ser discriminadas por sus rasgos grupales o culturales, es decir, por su

259/2011 expone que "la difusión, atendiendo a la forma y el ámbito en que se lleva a cabo y a lo que se difunde, implique un peligro cierto de generar un clima de hostilidad que pueda concretarse en actos específicos de violencia, odio o discriminación contra aquellos grupos o sus integrantes como tales" (FD $1^{\circ}$, 7).

${ }^{59}$ Sobre este problema ver BERNAL DEL CASTILLO, La discriminación en el Derecho Penal, cit. nota $\mathrm{n}^{\circ}$ 27 , pp. 37 y ss. 
BERNAL DEL CASTILLO, Jesús. "Política Criminal en España y discriminación xenófoba: la centralidad de los delitos de provocación a la discriminación”.

pertenencia a grupos étnicos, religiosos o raciales, rasgos que los diferencian de otros grupos y en los cuales aparecen de forma diferente: distinta raza, etnia o religión, diferente cultura.

En cambio, algunas de las circunstancias mencionadas en dicho precepto no obedecen a los elementos culturales o biológicos que caracterizan su pertenencia a un grupo por oposición a otro o, por lo menos, no son el elemento fundamental de los mismos: por ejemplo, la orientación sexual, la minusvalía o enfermedad no señalan más que características de personas individuales, no la existencia de un grupo o minoría social caracterizado por esas circunstancias, aunque puedan las personas que comparten dichas características formar grupos o asociaciones en defensa de sus derechos. Por esta razón creo que la inclusión de alguna de estas categorías en este delito particular no obedece al objetivo de la protección de la discriminación basada en la multiculturalidad o, por lo menos, en la mayoría de los casos una posible incitación contra ellos por reunir dichas características no obedecerá a dichas razones o no reunirá los requisitos de gravedad suficientes. ${ }^{60}$ De aquí que se puede afirmar que la exhaustividad en la mención de estas circunstancias no es realmente necesaria y puede obedecer a razones de conveniencia.

Por otra parte entiendo que muchas de esas expresiones son muy parecidas entre sí y en aras de una mayor simplificación debería reducirse su enumeración. En este sentido se podrían agrupar aquellas que representan un mismo o parecido fundamento y que implican una mayor gravedad, utilizando expresiones que además significan el contenido de los hechos a los que se incitan; por ejemplo, las palabra xenofobia y racismo son las que mejor cuadran desde esta perspectiva simplificadora. También en esta línea, la Decisión Marco del Consejo de 2008 utiliza estas dos mismas palabras, como marco de las conductas que se quiere prohibir, aunque a la hora de definir en particular el delito de provocación al odio o a la violencia amplía el catálogo de circunstancias:

"la incitación pública a la violencia o al odio dirigidos contra un grupo de personas o un miembro de tal grupo, definido en relación con la raza, el color, la religión, la ascendencia o el origen nacional o étnico".

A pesar de que mi opinión vaya en el sentido de simplificar la redacción del artículo 510.1 en cuanto a la enumeración de circunstancias, reconozco que por el momento es una propuesta que no encuentra fundamento desde el punto de vista legal, puesto que si hacemos una comparación sistemática, el resto de los tipos penales antidiscriminatorios

\footnotetext{
${ }^{60}$ En todo caso es un tema discutible. Por ejemplo la incitación al odio o a la violencia contra las mujeres puede encajar en este delito cuando la condición de ser mujer es una característica que en un grupo étnico o religioso implica una serie de consecuencias en su situación dentro del grupo o colectivo, de forma que en dicho colectivo el hecho de ser mujer la coloca en situación de inferioridad con los hombres y que son causas de prácticas contra ellas que se consideran normales o positivas cuando en realidad son inaceptables: mutilación genital, sometimiento al marido, etc. Si alguien difunde o expone esas ideas para incitar a los miembros de ese grupo a realizar actos delictivos o violentos contra las mujeres, entonces sí que estamos dentro del ámbito de la provocación punible del artículo 510.1, porque se está animando a que se lesionen derechos de un miembro de ese grupo que están protegidos por el principio de igualdad y dignidad de la persona. Es el caso del libro publicado por el imán de Fuengirola, resuelto por el Juzgado de lo Penal $n^{\circ} 3$ de Barcelona, en sentencia de 12 de enero de 2004.
} 
Polit. crim. Vol. 9, № 18 (Diciembre 2014), Art. 3, pp. 371-399.

[http://www.politicacriminal.cl/Vol_09/n_18/Vol9N18A3.pdf]

siguen este sistema de una enumeración exhaustiva; en concreto, así lo hace la agravante discriminatoria del art. 22.4 , las injurias discriminatorias del art. 510.2, los delitos de discriminación directa de los artículos 511 y 512, las asociaciones discriminatorias del art. $515.5^{\circ}$ y la discriminación laboral del artículo $314 .^{61}$

\section{Conclusiones}

En las páginas anteriores he procurado realizar algunas aportaciones al problema de los conflictos entre mayorías y minorías en las modernas sociedades multiculturales, sobre todo en el mundo occidental y más concretamente en España.

La realidad de una conflictividad cultural e ideológica causada por la nueva composición social procedente de una inmigración masiva es objetivamente una cuestión que afecta al Derecho Penal y que debe ser abordado desde una Política Criminal efectiva y respetuosa tanto con los fines del Derecho Penal como con la tradición política y cultural europea.

Desde esta perspectiva, no veo posible la adopción de un modelo político criminal comunitario, que de forma general plantee la defensa de unos derechos culturales de las minorías en Europa en pie de igualdad con el sistema de valores derivado de una concepción fuerte de los derechos humanos. La política criminal liberal en sus propuestas clásicas tampoco es efectiva en cuanto se limita a garantizar la vigencia principio formal ante la ley de todos los residentes en un país, desconociendo la realidad sociológica de valores culturales minoritarios y dando lugar a una asimilación de los inmigrantes, que no soluciona sino incrementa la conflictividad social. Por ello he propuesto un sistema de intervención del Derecho Penal en los conflictos multiculturales que se proponga la tipificación de delitos discriminatorios, entendidos como ataques al derecho a no ser discriminado, derecho personalista que se deriva de la dignidad de la persona y que se proyecta en la seguridad de los individuos y de los colectivos que los agrupan a no verse rechazados por razón de sus características culturales, entendiendo por tales el conjunto de elementos raciales, nacionales, religiosos y valorativos que definen a la persona y la integran en un grupo cultural y social.

La protección penal del derecho a no ser discriminado debe mantenerse dentro de unos límites, dado el carácter subsidiario del Derecho Penal. La proliferación de delitos discriminatorios en los diversos ordenamientos no impide observar la centralidad de la provocación o incitación a la discriminación, al racismo y a la xenofobia, como conducta que representa la moderna orientación político criminal en la Unión Europea.

El estudio de este delito lo he referido principalmente a su regulación en el Derecho Penal español en su artículo 510.1. Su ubicación sistemática es acorde con el fundamento de la punibilidad de esta conducta como ataque al derecho a no ser discriminado. La concreción de los sujetos pasivos como grupos y colectivos no invalida el carácter personalista del bien

\footnotetext{
${ }^{61}$ En el caso de la normativa europea, la propia Decisión Marco del Consejo de 2008 permite que cada Estado, en el desarrollo de esta decisión, extienda los delitos contra grupos de personas definidos con arreglo a otros criterios distintos de los de raza, color, religión, ascendencia u origen nacional o étnico, como por ejemplo la posición social o las convicciones políticas.
} 
BERNAL DEL CASTILLO, Jesús. "Política Criminal en España y discriminación xenófoba: la centralidad de los delitos de provocación a la discriminación”.

jurídico, por cuanto los actos de incitación a la discriminación afectan a todos y cada uno de los miembros de las minorías.

Mayores problemas presenta la definición de los elementos objetivos y subjetivos del tipo. La anticipación de la punición penal a actos de incitación a la discriminación, al odio y a la violencia previos a la discriminación misma o a los actos de violencia, exigen que el concepto de incitación se interprete de una forma que manifieste la real peligrosidad de esas conductas para los derechos de los sujetos pasivos. Acepto, por ello, la vinculación del concepto de provocación a la discriminación con el concepto general, mucho más estricto, de provocación para cometer un delito del artículo 18 del Código Penal.

No obstante me permito hacer una interpretación flexible de dicha dependencia en aras de garantizar la efectiva aplicación del artículo 510.1. En concreto entiendo que la provocación debe tratarse no sólo de una incitación directa a cometer un delito concreto de discriminación o violencia, sino también una incitación a realizar hechos no tipificados expresamente como delitos pero que encierran una lesión grave al ejercicio de los derechos de individuos y grupos que sean esenciales para su integración y desarrollo. También entiendo que junto a una incitación directa cabe aceptar aquella que de una forma indirecta en cuanto a la forma de expresar el mensaje, resulta lo suficientemente clara para deducir su carácter incitador y su peligrosidad.

Finalmente, aunque entiendo que sería suficiente la reducción de los motivos discriminatorios que integran el elemento subjetivo del injusto a los supuestos de motivos racistas y xenófobos, la enumeración exhaustiva de los mismos que realiza el artículo 510.1 es coherente con las fórmulas utilizadas en el resto de los delitos de discriminación regulados en el Código Penal español.

Las reflexiones que he realizado coinciden en mayor o menor medida con la doctrina mayoritaria en España y, por ello, no resulta extraño que el Proyecto de Reforma del Código Penal español, presentado ante las Cortes Generales españolas en el presente año $2013,{ }^{62}$ incorpore en relación al delito de provocación discriminatoria alguna de las ideas que he defendido en este trabajo. ${ }^{63}$

${ }^{62} \mathrm{http}$ ://www.congreso.es/public oficiales/L10/CONG/BOCG/A/BOCG-10-A-66-1.PDF

63 "Art. 510: 1. Serán castigados con una pena de prisión de uno a cuatro años y multa de seis a doce meses:

a) Quienes fomenten, promuevan o inciten directa o indirectamente al odio, hostilidad, discriminación o violencia contra un grupo, una parte del mismo o contra una persona determinada por razón de su pertenencia a aquél, por motivos racistas, antisemitas u otros referentes a la ideología, religión o creencias, situación familiar, la pertenencia de sus miembros a una etnia, raza o nación, su origen nacional, su sexo, orientación o identidad sexual, enfermedad o discapacidad.

b) Quienes produzcan, elaboren, posean con la finalidad de distribuir, faciliten a terceras personas el acceso, distribuyan, difundan o vendan escritos o cualquier otra clase de material o soportes que por su contenido sean idóneos para fomentar, promover, o incitar directa o indirectamente al odio, hostilidad discriminación o violencia contra un grupo, una parte del mismo, o contra una persona determinada por razón de su pertenencia a aquél, por motivos racistas, antisemitas u otros referentes a la ideología, religión o creencias, situación familiar, la pertenencia de sus miembros a una etnia, raza o nación, su origen nacional, su sexo, orientación o identidad sexual, enfermedad o discapacidad.

c) Quienes nieguen, trivialicen gravemente o enaltezcan los delitos de genocidio, de lesa humanidad o contra las personas y bienes protegidos en caso de conflicto armado, o enaltezcan a sus autores, cuando se hubieran 
Polít. crim. Vol. 9, № 18 (Diciembre 2014), Art. 3, pp. 371-399.

[http://www.politicacriminal.cl/Vol_09/n_18/Vol9N18A3.pdf]

\section{BIBLIOGRAFÍA}

BASILE, Fabio, "Il diritto penale nelle società multiculturali: i reati culturalmente motivati", Polít. crim., vol. 6, $\mathrm{n}^{\mathrm{o}} 12$ (2011), Art. 4, pp. 339-386, en: http://politicacriminal.cl/Vol 06/n_12/Vol6N12A4.pdf

BENLLOCH PETIT, Guillermo, "El Derecho Penal ante el conflicto político: Reflexiones en torno a la relevancia penal de determinados fines, opiniones o motivos políticos o ideológicos y su legitimidad", Anuario de Derecho Penal y Ciencias Penales, t.54 (2001), pp. 175-227.

BERNAL DEL CASTILLO, Jesús, La discriminación en el Derecho Penal, Granada: Ed. Comares, 1998.

BORJA JIMÉNEZ, Emiliano, Introducción a las bases del Derecho Penal indígena, Valencia: Tirant lo Blanch, 2000.

Diversidad cultural: conflicto y derecho, Valencia: Tirant Monografías, 2006.

CANCIO MELIA, Manuel, en: JORGE BARREIRO, Agustín, RODRÍGUEZ MOURULlO, Gonzalo (coord.), Comentarios al Código Penal, Madrid, Ed. Civitas, 1997, pp. 1272- 1337.

CANO PAÑOS, Miguel Ángel, "Las sociedades paralelas en Europa en el contexto de la inmigración y su eventual influencia en la radicalización islamista de sus miembros", en: BERNAL DEL CASTILLO, Jesús (dir.), Delito y minorías en países multiculturales, Barcelona: Ed. Atelier, 2014, pp. 207-229.

CARNEVALI RODRÍGUEZ, Raúl, "El multiculturalismo: un desafío para el Derecho Penal moderno", Polít. crim., $\mathrm{n}^{\mathrm{o}} 3$ (2007) A6, pp.1-28; http://www.politicacriminal.cl/n_03/a_6_3.pdf

CORNACCHIA, Luigi, "Justicia transicional en una sociedad multicultural", en: CORNACCHIA, Luigi; SÁNCHEZ-OSTIZ, Pablo, (coords.), Multiculturalismo y Derecho Penal, Madrid: Aranzadi, 2012, pp. 69-80.

CUEVA FERNÁNDEZ, Ricardo, "A propósito de la Sentencia del Tribunal Supremo 259/2011: Discurso del odio, incitación y derecho al honor colectivo. ¿Una nueva vuelta de tuerca contra la prohibición del hate speech?", Eunomia. Revista en Cultura de la Legalidad, $\mathrm{n}^{\circ} 2$ (2012), pp. 99-108, en: http://eunomia.tirant.com/?p=963

DE MAGLIE, Cristina, I reati culturalmente motivati. Ideologie e modelli penali, Firenze: Ed. ETS, 2010. Traducción española de MACÍAS CARO, Víctor Manuel, Madrid: Marcial Pons, 2012.

DOPICO GÓMEZ-ALLER, Jacobo, "Delitos cometidos por motivos discriminatorios: una aproximación desde los criterios de legitimación de la pena", Anuario de Derecho Penal y Ciencias Penales, tomo LVII (2004), pp. 143-175.

ESER, Albin "The law of Incitement and the use of speech to incite others to commit Criminal Acts: German Law in Comparative Perspective", en: KRETZMER, David;

cometido contra un grupo o una parte del mismo, o contra una persona determinada por razón de su pertenencia al mismo, por motivos racistas, antisemitas u otros referentes a la ideología, religión o creencias, la situación familiar o la pertenencia de sus miembros a una etnia, raza o nación, su origen nacional, su sexo, orientación o identidad sexual, enfermedad o discapacidad, cuando de este modo se promueva o favorezca un clima de violencia, hostilidad, odio o discriminación contra los mismos". 
BERNAL DEL CASTILLO, Jesús. "Política Criminal en España y discriminación xenófoba: la centralidad de los delitos de provocación a la discriminación".

KERSHMANN, Francine (dirs.), Freedom of speech and Incitement Against Democracy, The Hague: Kluwer Law International, 2000.

FERREIRA MONTE, Mario, "Multiculturalismo y Derecho Penal en el espacio lusófono. Prueba de una solución de restauración para el problema de los delitos motivados culturales", en: CORNACCHIA, Luigi; SÁNCHEZ-OSTIZ, Pablo (coords.), Multiculturalismo y Derecho Penal, Madrid: Aranzadi, 2012, pp. 117-130.

GARCÍA ÁLVAREZ, Pastora, El derecho Penal y la discriminación. Especial referencia al extranjero como víctima de discriminaciones penalmente relevantes, Valencia: Tirant Lo Blanch, 2004.

GARCIA VITORIA, Aurora, "Extranjería y discriminación: análisis dogmático y jurisprudencial”, en: ZUGALDÍA ESPINAR, José Miguel; PÉREZ ALONSO, Esteban J. (dirs.) El Derecho Penal ante el fenómeno de la inmigración, Valencia: Tirant Lo Blanch, 2007, pp. 319-363.

JOPKE, Christian, "Minority Rights for Immigrants? Multiculturalism versus Antidiscrimination", Israeli Law Review, vol. 43 (2010), pp. 49-66.

LANDA GOROSTIZA, Jon Mirena, La protección penal frente a la xenofobia, Bilbao: Universidad del País Vasco, 1999.

"Incitación al odio: evolución jurisprudencial (1995-2011) del art. 510 CP y propuesta de lege lata", Revista de Derecho Penal y Criminología, no 7 (2012), pp. 297-346.

LAURENZO COPELLO, Patricia "La discriminación en el Código Penal de 1995", Estudios Penales y Criminológicos” " $\mathrm{n}^{\circ}$ XIX (1996), pp. 219-288.

"Marco de protección jurídico-penal del derecho a no ser discriminado. Racismo y xenofobia", Cuadernos de Derecho Judicial n 1 (1996), pp. 217-242.

MODOLELL GONZÁLEZ, José Luis, "Breves consideraciones sobre la posible responsabilidad personal de sujetos pertenecientes a grupos culturalmente diferenciados (casos del indígena y costumbres de origen afroamericano)", Derecho Penal y pluralidad cultural. Anuario de Derecho Penal, 2006, pp. 273-286, en: http://perso.unifr.ch/derechopenal/assets/files/anuario/an_2006_14.pdf

PORTILLA CONTRERAS, Guillermo; POMARES CINTAS, Esther, "Derecho Penal multicultural y el sistema de justicia comunitaria”, en: BERNAL DEL CASTILLO, Jesús (dir.), Delito y minorías en países multiculturales, Barcelona: Ed. Atelier, 2014, pp. 231-252.

QUINTERO OLIVARES, Gonzalo, “El derecho penal de la globalización”, en: ZÚÑIGA RODRÍGUEZ, Laura; MÉNDEZ RODRÍGUEZ, Cristina; DIEGO DÍAZ-SANTOS, Rosario, (coords.) El Derecho Penal ante la globalización, Madrid: Ed. Colex, 2002, pp. 11-25.

RETORTILlO OSUNA, Álvaro; OVEJERO BERNAL, Anastasio; CRUZ SOUSA, Fátima; LUCAS MANGAS, Susana; ARIAS MARTÍNEZ, Benito, "Inmigración y modelos de integración: entre la asimilación y el multiculturalismo", Revista Universitaria de Ciencias del Trabajo, $\mathrm{n}^{\mathrm{o}} 7$ (2008), pp. 124-139, en: http://www.ruct.uva.es/pdf/Revista\%207/7106.pdf

ROCA DE AGAPITO, Luis, "Delitos culturalmente motivados", en: BERNAL DEL CASTILLO (dir.), Delito y minorías en países multiculturales, Barcelona: Ed. Atelier, 2014, pp. 177-205. 
Polít. crim. Vol. 9, Nº 18 (Diciembre 2014), Art. 3, pp. 371-399.

[http://www.politicacriminal.cl/Vol_09/n_18/Vol9N18A3.pdf]

RODRÍGUEZ YAGÜE, Cristina, "Una propuesta de clasificación de los delitos de discriminación en el Código Penal español", Publicaciones del Instituto de Derecho Penal Europeo e Internacional, dos mil-tres mil, 2007, Universidad de Castilla La Mancha $\mathrm{n}^{\mathrm{o}}$ 11, pp. 1-25.

SANTAMARÍA, Francisco, ¿Un mundo sin Dios? La religión bajo sospecha, Madrid: Ed. Rialp, 2012.

SÁNCHEZ-OSTIZ GUTIÉRREZ, Pablo, Fundamentos de Política Criminal. Un retorno a los principios, Madrid: Marcial Pons, 2012.

SILVA SÁNCHEZ, Jesús María, "Retos científicos y retos políticos de la Ciencia del Derecho Penal”, ¿Crisis del sistema dogmático del delito?, Cuadernos de Conferencias y artículos $\mathrm{n}^{\circ} 40$ (2007), Universidad Externado de Colombia.

La expansión del Derecho Penal. Aspectos de la política criminal en las sociedades postindustriales, $2^{\mathrm{a}}$ ed., Madrid: Ed. Civitas, 2001.

STOPLER, Gila, "Rights in Immigration: The veil case as a test case", Israeli Law Review, vol. 43 (2010), pp. 183-217.

TAPIA BALLESTEROS, Patricia, La discriminación laboral. Análisis del artículo 314 del Código Penal, Valencia: Tirant Monografías, 2014.

VIOLA, Francesco, "Diritti fondamentali e multiculturalismo", en: BERNARDI, Alessandro (coord.), Multiculturalismo, diritti humani, pena, Milano: Giuffré, 2006. 